\title{
Preparation of the Endometrium for Frozen Embryo Transfer: A Systematic Review
}

\author{
Sezcan Mumusoglu ${ }^{1}$, Mehtap Polat ${ }^{2}$, Irem Yarali Ozbek ${ }^{2}$, Gurkan Bozdag ${ }^{1}$, \\ Evangelos G. Papanikolaou ${ }^{3}$, Sandro C. Esteves ${ }^{4,5}$, Peter Humaidan ${ }^{5,6}$ \\ and Hakan Yarali ${ }^{1,2 *}$ \\ ${ }^{1}$ Department of Obstetrics and Gynecology, Hacettepe University School of Medicine, Ankara, Turkey, ${ }^{2}$ Anatolia IVF and \\ Women Health Centre, Ankara, Turkey, ${ }^{3}$ Nature IVF Unit, Thessaloniki, Greece, ${ }^{4}$ Androfert, Andrology and Human \\ Reproduction Clinic, Referral Center for Male Reproduction, Campinas, Brazil, ${ }^{5}$ Department of Clinical Medicine, Aarhus \\ University, Aarhus, Denmark, ${ }^{6}$ The Fertility Clinic, Skive Regional Hospital Resenvej 25, Skive, Denmark
}

OPEN ACCESS

Edited by:

Richard Ivell,

University of Nottingham,

United Kingdom

Reviewed by:

Panagiotis Drakopoulos,

University Hospital Brussels, Belgium

Joaquin Llacer,

Instituto Bernabeu, Spain

${ }^{*}$ Correspondence:

Hakan Yarall

hyarali@hacettepe.edu.tr;

hyarali@anatoliatupbebek.com.tr

Specialty section:

This article was submitted to Reproduction,

a section of the journal

Frontiers in Endocrinology

Received: 30 March 2021 Accepted: 23 June 2021

Published: 09 July 2021

Citation:

Mumusoglu S, Polat M, Ozbek IY,

Bozdag G, Papanikolaou EG,

Esteves SC, Humaidan P and Yarali H

(2021) Preparation of the

Endometrium for Frozen Embryo

Transfer: A Systematic Review.

Front. Endocrinol. 12:688237.

doi: 10.3389/fendo.2021.688237
Despite the worldwide increase in frozen embryo transfer, the search for the best protocol to prime endometrium continues. Well-designed trials comparing various frozen embryo transfer protocols in terms of live birth rates, maternal, obstetric and neonatal outcome are urgently required. Currently, low-quality evidence indicates that, natural cycle, either true natural cycle or modified natural cycle, is superior to hormone replacement treatment protocol. Regarding warmed blastocyst transfer and frozen embryo transfer timing, the evidence suggests the $6^{\text {th }}$ day of progesterone start, $\mathrm{LH}$ surge +6 day and $\mathrm{hCG}+7$ day in hormone replacement treatment, true natural cycle and modified natural cycle protocols, respectively. Time corrections, due to inter-personal differences in the window of implantation or day of vitrification (day 5 or 6), should be explored further. Recently available evidence clearly indicates that, in hormone replacement treatment and natural cycles, there might be marked inter-personal variation in serum progesterone levels with an impact on reproductive outcomes, despite the use of the same dose and route of progesterone administration. The place of progesterone rescue protocols in patients with low serum progesterone levels one day prior to warmed blastocyst transfer in hormone replacement treatment and natural cycles is likely to be intensively explored in near future.

Keywords: frozen embryo transfer, hormone replacement treatment cycle, natural cycle, true natural cycle, modified natural cycle, individualized approach

\section{INTRODUCTION}

Over the last decade, efficient and safe vitrification techniques, alongside an increase in "freeze-all" cycles have contributed to a marked increase in frozen embryo transfer (FET) cycles globally (1). The number of FET cycles started to surpass fresh transfer in the United States and Australia and New Zealand in 2015 and 2016, respectively (1). Among all embryo transfers, the proportion of FET cycles was $77.0 \%$ as reported by the most recent update from the United States nationwide database (2). In Europe, a similar trend, however with a certain delay is seen; among all embryo transfers, the proportion of FET cycles increased from $28 \%$ in 2010 to $34 \%$ in $2016(3,4)$. The main contributor of 
the increasing trend for FET is an increase in freeze-all cycles; in 2016 , of all oocyte retrievals, the rates of freeze-all were $26.5 \%$, 19.2\% and 8.5\% in Australia and New Zealand, United States and Europe, respectively (1). The increasing trend to perform more pre-implantation genetic testing cycles for aneuploidy, especially in the United States (2), has also contributed to an increase in the total number of FET cycles (1).

Despite the increase in FET, the most optimal priming protocol of the endometrium is still a matter of debate (5). The available FET protocols are i) true natural cycle (t-NC) with/ without luteal phase support (LPS) ii) modified NC (modifiedNC) with/without LPS, iii) hormone replacement treatment (HRT) with or without gonadotropin releasing hormone ( $\mathrm{GnRH}$ ) analogue suppression, and iv) mild ovarian stimulation (mild-OS) using gonadotropins, clomiphene citrate (CC), or letrozole (Table 1).

In the current systematic review, we aim to compare different FET protocols in terms of reproductive, obstetric and maternal outcomes. Following an overview of the available FET protocols, a special emphasis will be given to suggest an individualized approach if live birth rates (LBRs) are to be increased.

\section{MATERIALS AND METHODS}

PubMed and EMBASE databases were searched for studies that included the keywords (endometrial preparation, frozen embryo transfer, oocyte donation, egg donation, cryo-thawed, natural cycle, frozen embryo transfer, modified natural cycle embryo transfer, artificial frozen cycle, artificial frozen cycle with gonadotropin suppression) and $\mathrm{MeSH}$ terms (cryopreservation and pregnancy). The search was restricted to manuscripts published in peer review journals and abstracts in English language during 1991-2021. To review the topic of "Endometrium preparation for FET" advantages/disadvantages of different FET protocols and the potential impact of different FET protocols on reproductive outcomes are discussed based on the data, derived firstly from randomized controlled trials (RCT), meta-analyses, and secondly from large prospective cohort studies, whenever available.

TABLE 1 | Endometrium preparation protocols for frozen embryo transfer (FET).

Hormone replacement treatment (HRT)
•HRT with GnRH-a suppression
$\bullet H R T$ without GnRH-a suppression
True natural (t-NC) cycle
$\bullet$ t-NC with luteal phase support
•t-NC without luteal phase support
Modified natural (modified-NC) cycle
•Modified-NC with luteal phase support
•Modified-NC without luteal phase support
Mild ovarian stimulation (Mild-OS)
•Clomiphene Citrate (CC)/Aromatase Inhibitor (Letrozole)/Follicle Stimulating
Hormone (FSH)

\section{ENDOMETRIAL PRIMING PROTOCOLS FOR FROZEN EMBRYO TRANSFER}

The two main endometrial priming protocols for FET are HRT and natural cycle (NC); less commonly, mild-OS is employed (6). In the HRT cycle, suppression of follicular growth, endometrial proliferation and subsequent secretory transformation is achieved by the timely administration of exogenous estradiol $\left(\mathrm{E}_{2}\right)$ and progesterone $(\mathrm{P})$. In $\mathrm{NC}$, however, endogenous $\mathrm{E}_{2}$ and $\mathrm{P}$ secreted in a spontaneous cycle will prime the endometrium.

A FET cycle could be considered immediately after a failed fresh transfer cycle, as this results in a similar clinical pregnancy rate $(\mathrm{CPR})$ to that postponed to a later time (7). Moreover, performing a FET cycle without delay will reduce the time to pregnancy and the psychological burden associated with waiting (8).

\section{Hormone Replacement Treatment (HRT) Estrogen Administration}

Treatment with oral $\mathrm{E}_{2}$ is started on the first, second or third day of the cycle to prime the endometrium and suppress spontaneous follicle growth. Estradiol is administered either at a fixed constant dose (6 mg daily) or in an incremental fashion; although many regimens have been used for the incremental increase of $\mathrm{E}_{2}$, the most commonly used is $2 \mathrm{mg}$ /day during days $1-7,4 \mathrm{mg}$ /day during days $8-12,6 \mathrm{mg}$ /day during days 13 to embryo transfer (9). Although no RCT compared the fixed and step-up regimens, a large retrospective study performed in 8,254 oocyte donation cycles reported comparable LBRs (33.0 vs $32.5 \%$, respectively) (9). In terms of estrogens, natural as well as synthetic $\mathrm{E}_{2}$ can be used, but again to our knowledge, no trial compared these two forms of $\mathrm{E}_{2}$ usage in HRT cycles. Different routes, including oral (micronized estradiol or estradiol valerate), vaginal (estradiol valerate) or transdermal (estradiol gel), can be used for the administration of $\mathrm{E}_{2}$ with comparable reproductive outcomes (5). Although vaginal $\mathrm{E}_{2}$ may be administered in a ring, tablet or cream forms, local vaginal irritation, discomfort, and unsatisfactory absorption especially when administered together with vaginal $\mathrm{P}$ are the reasons why the vaginal route of $E_{2}$ administration is not the preferred route by the majority of IVF clinics (10). Thus, an international survey, conducted at 179 fertility units in a total of 56 countries, reported that, in 39,152 FET cycles, the oral $\mathrm{E}_{2}$ route was the most commonly used (84\%), followed by transdermal (9\%) and vaginal (3\%) routes (6).

The conversion of doses, using different routes/types can be calculated as follows: $0.75 \mathrm{mg}$ oral micronized estradiol $=1.25 \mathrm{~g}$ of transdermal estradiol gel $=1 \mathrm{mg}$ oral/vaginal estradiol valerate (10). Importantly, a recent meta-analysis reported no difference between transdermal $\mathrm{E}_{2}$ and oral $\mathrm{E}_{2}$ as regards $\mathrm{CPR}(\mathrm{OR}=0.86$, $95 \%$ CI 0.59 - 1.25; $\mathrm{n}=504 ; 3$ studies; low-quality evidence, $\mathrm{I}^{2}=$ $58 \%)$ and miscarriage rates $(\mathrm{OR}=0.55,95 \%$ CI $0.27-1.09 ; \mathrm{n}=414$; 2 studies; low-quality evidence; $\left.\mathrm{I}^{2}=0 \%\right)(5)$.

The detrimental impact of elevated day $2 / 3$ serum $\mathrm{P}_{4}$ levels on pregnancy rates in HRT-FET cycles has not been clearly elucidated. Although, data is limited, elevated basal levels of serum $\mathrm{P}_{4}$ levels $(>1.5 \mathrm{ng} / \mathrm{ml})$ does not seem to have negative 
impact on reproductive outcome (11). Usually, after 12 - 14 days of $\mathrm{E}_{2}$ administration, vaginal ultrasound examination is performed for endometrial thickness measurement and to confirm the absence of a leading follicle. This long $\mathrm{E}_{2}$ priming period may be unnecessary, as 5-7 days may suffice for adequate endometrial priming according to early studies $(10,12)$. Caution, however, is warranted, since a higher miscarriage rate has been reported using a shorter $\mathrm{E}_{2}$ priming period ( $<10$ days) (13). Conversely, $\mathrm{E}_{2}$ administration may be prolonged for up to 28 days (14) or even 36 days (15), if necessary, without compromising reproductive outcomes and, thus, offering a greater flexibility of timing of FET (14). When the endometrial thickness $>7 \mathrm{~mm}$, P supplementation is commenced, and timing of FET is scheduled accordingly.

Suppression of the hypothalamus-pituitary axis by a GnRHanalogue can be performed prior to HRT. Although GnRHagonists are commonly used for this purpose, to our knowledge, there is only one RCT comparing a 7-day regimen with daily GnRH-antagonist administration $(n=287)$ to a single dose of long-acting $\mathrm{GnRH}$-agonist $(\mathrm{n}=276)$ in an oocyte donation model, reporting similar ongoing pregnancy rates (OPRs) (46.7\% vs 39.9\%, respectively; adjusted $\mathrm{OR}=1.42$, 95\%CI 0.97 2.09) (16).

Although HRT with suppression is highly efficient to avoid ovulation, HRT without suppression is more patient friendly. However, premature ovulation leading to cycle cancellation, encountered in $1.9 \%$ to $7.4 \%$ of the cycles, could be the main drawback of an HRT protocol without suppression $(17,18)$. In a recent Cochrane meta-analysis (5), only one RCT comparing LBR in HRT cycles with or without GnRH-agonist suppression was identified. In this trial, GnRH suppression improved LBR per initiated cycle $(20.0 \%$ vs $8.5 \%$; OR=2.62, 95\% CI 1.19 - 5.78; $\mathrm{n}=234$; one study; low-quality evidence) (19). However, the same Cochrane meta-analysis reported comparable $\mathrm{CPR}(\mathrm{OR}=1.08$, 95\% CI 0.82 - 1.43; $\mathrm{n}=1289$; eight studies; low-quality evidence, $\left.\mathrm{I}^{2}=20 \%\right)$, miscarriage rates $(\mathrm{OR}=0.85,95 \%$ CI 0.36 - 2.00; $\mathrm{n}=828$; four studies; low-quality evidence; $\mathrm{I}^{2}=0 \%$ ), cycle cancellation rates $(\mathrm{OR}=0.49,95 \%$ CI 0.21 - 1.17; $\mathrm{n}=530$; two studies; low-quality evidence; $\mathrm{I}^{2}=0 \%$ ) and endometrial thickness (MD -0.08, 95\% CI -0.33; 0.16; n=697; four studies; low-quality evidence; $\mathrm{I}^{2}=4 \%$ ) with or without GnRH-suppression (5).

To conclude, in HRT cycle, $\mathrm{E}_{2}$ priming with oral or transdermal routes has similar efficacy. The optimal duration for $\mathrm{E}_{2}$ priming is between 10 to 36 days, which offers a greater flexibility of timing of FET without compromising reproductive outcomes. Although pituitary suppression with $\mathrm{GnRH}$-agonist decreases the cycle cancelation rate, HRT without suppression is more patient friendly and is associated with similar CPRs when compared with those attained with GnRH-agonist suppression.

\section{Progesterone Administration}

Optimal exposure of $\mathrm{P}$, in terms of timing and concentration, is crucial for the establishment and maintenance of an ongoing pregnancy. In this context, the route, dose and starting date of $\mathrm{P}$ should be taken into consideration. The available routes for $\mathrm{P}$ administration in an HRT cycle are vaginal, intramuscular (im), subcutaneous (sc), oral and rectal. The vaginal administration, distinct form the other routes, has a first-pass uterine effect (2022), and until now, there is paucity of data on the use of oral (dydrogesterone) (23) sc (24) and rectal (25) routes.

Different forms of vaginal $\mathrm{P}$ can be used, including bioadhesive gels, micronized tablets, capsules or suppositories. Of note, the typical doses used for vaginal $\mathrm{P}$ administration in an HRT cycle, are those extrapolated from fresh embryo transfer cycles; i) bio-adhesive $\mathrm{P}$ gel $(1 \times 90 \mathrm{mg})$, ii) micronized $\mathrm{P}$ tablet (3x100 mg), iii) P capsule (3x200 mg), iv) suppository $(2 \times 400$ $\mathrm{mg})$. There is paucity of comparative data on different doses of vaginal $\mathrm{P}$ and the subsequent reproductive outcomes.

In a retrospective study, progesterone bio-adhesive gel once daily (90 mg/day; $\mathrm{n}=161$ ) was compared with twice daily administration (90 mg/12 hours; $\mathrm{n}=185$ ) in the HRT cycle, and both the implantation $(7.6 \%$ vs $20.2 \%, \mathrm{p}=0.0001)$ and delivery rates $(8.7 \%$ vs $20.5 \%, \mathrm{p}=0.002)$ were significantly higher with the twice-daily regimen (26). Moreover, in a more recent retrospective study of 2,010 HRT-FET cycles, the use of 1200 mg $\mathrm{P}$ capsules was associated with a significantly higher CPR when compared with a daily dose of $900 \mathrm{mg}$ (27). Definitely, more studies are warranted to delineate the optimum dosing of various vaginal forms of P. More importantly, in the personalized medicine era, as will be discussed in the "Individualized FET Approach" section, monitoring the luteal serum $\mathrm{P}_{4}$ level is crucial to increase reproductive outcomes.

Since there is no corpus luteum in an HRT cycle, all the available $\mathrm{P}$ derives from exogenous administration. Vaginal $\mathrm{P}$ is more commonly used in Europe whereas im $\mathrm{P}$ has been preferred in the US. The debate whether vaginal or im $\mathrm{P}$ is superior, in terms of the reproductive outcome, is still ongoing. Thus, some retrospective studies reported better reproductive outcomes using the im route $(28,29)$, whereas others reported similar outcomes $(30,31)$. In total there are three RCTs comparing the im and vaginal routes in HRT-FET cycles, and similar clinical pregnancy rates were reported in two RCTs $(32,33)$. More recently, a RCT using vitrified blastocyst transfer in HRT cycles compared the OPRs in three arms consisting of $200 \mathrm{mg}$ vaginal tablet $\mathrm{P}$ twice daily, $50 \mathrm{mg}$ daily im P, only, and $200 \mathrm{mg}$ vaginal $\mathrm{P}$ twice daily supplemented with $50 \mathrm{mg}$ im $\mathrm{P}$ every third day (34). In interim analysis, a significantly lower OPR was reported in the vaginal P-only group: 31\% compared with the other two groups (50\% and $47 \%$ ), which was mainly caused by a significantly higher biochemical loss and miscarriage rate rather than a lower positive human chorionic gonadotropin (hCG) rate in the vaginal progesterone-only group. Hence, the vaginal Ponly arm was prematurely terminated (34). Patient recruitment continued for the remaining two arms to result in a total of 1,125 patients (1,060 FET cycles) for the whole study. Very recently, the results of the final analysis were reported. The LBR was significantly lower in the vaginal P-only arm (27\%) when compared with im P (44\%) or vaginal P supplemented with im $\mathrm{P}$ every third day (46\%); however, no significant difference was noted between im $\mathrm{P}$ or vaginal $\mathrm{P}$ supplemented with im $\mathrm{P}$ every third day (35). One of the limitations of that study is heterogeneity as regards timing of FET in the three arms; 
vitrified blastocysts were warmed and transferred on the $5^{\text {th }}$ day of $\mathrm{P}$ in the vaginal $\mathrm{P}$ administration (with or without im $\mathrm{P}$ ), whereas in subjects assigned to the im $\mathrm{P}$ only group, vitrified blastocysts were warmed and transferred on the $6^{\text {th }}$ day of $\mathrm{P}$ administration. Such difference in scheduling may introduce bias as $\mathrm{P}$ exposure duration until the embryo was transferred differed among groups. Moreover, serum $\mathrm{P}_{4}$ levels were not available. In our recent retrospective cohort study of 475 consecutive, day-5/6 vitrified-warmed HRT cycles, we were not able to reproduce the findings of Devine et al. study (36). Thus, intramuscular supplementation with $50 \mathrm{mg} \mathrm{P}$ every third day, did not enhance the OPR compared to vaginal progesterone-only. Moreover, the route (vaginal vs im) was not an independent predictor of OPR when tested in a multivariate logistic regression analysis. However, unlike Devine's study, progesterone vaginal gel (twice daily), but not a vaginal tablet, was used in our study.

A recent retrospective study by Vuong et al., in HRT cycles, compared reproductive outcomes between vaginal micronized $\mathrm{P}$ $400 \mathrm{mg}$ twice daily plus oral dydrogesterone $10 \mathrm{mg}$ twice daily $(\mathrm{n}=732)$ versus vaginal micronized P $400 \mathrm{mg}$ twice daily alone ( $n=632$ ) for LPS (37). Significantly higher LBR (46.3\% vs. $41.3 \%$, respectively, $\mathrm{RR}=1.30,95 \% \mathrm{CI} 1.01-1.68, \mathrm{p}=0.042)$, and lower miscarriage rate $(3.4 \%$ vs. $6.6 \%$; respectively, $\mathrm{RR}=0.51,95 \% \mathrm{CI}$ $0.32-0.83 ; \mathrm{p}=0.009$ ) have been reported with vaginal micronized plus oral dydrogesterone when compared with vaginal micronized P only (37).

The optimal length of luteal support in HRT cycles has never been explored in a RCT, but from a physiological point of view, $\mathrm{P}$ should be continued until the luteo-placental shift occurs which is still a matter of debate (38-40), and generally the common practice is to continue until $10^{\text {th }}-12^{\text {th }}$ weeks of gestation (6).

In conclusion, there is paucity of data on the impact of different routes (vaginal, im, sc, oral or rectal routes) of $\mathrm{P}$ administration on reproductive outcome in HRT cycles. Vaginal administration is the most commonly used route. Future studies are warranted to delineate the optimum dosing of various vaginal forms of $\mathrm{P}$. Since there is no corpus luteum in HRT cycles, $\mathrm{P}$ should be continued until the $10^{\text {th }} 12^{\text {th }}$ weeks of gestation.

\section{Day of Starting Progesterone Administration}

The interaction between embryo and a receptive endometrium is a complex molecular process essential for successful implantation (41). It is generally considered that once $\mathrm{P}_{4}$ levels reach a critical threshold, they set into motion a well-timed and orderly secretory transformation of the endometrium leading to receptivity (42).

There is paucity of data on the impact of the length of the $\mathrm{P}$ exposure on the reproductive outcome. To our knowledge, there are four RCTs, three published in peer review journals (43-45) and one abstract (46). Of those 4 RCTs, embryo transfer was carried out at the cleavage stage in two trials $(43,44)$, whereas the remaining two had embryo transfer at the blastocyst stage (46). The earliest RCT, conducted in an oocyte donation model and transferring day-3 embryos, compared $\mathrm{P}$ start on the $2^{\text {nd }}$ (egg retrieval+1 day; Group C; n=91), $3^{\text {rd }}$ (egg retrieval day, Group B; $\mathrm{n}=94)$ or $4^{\text {th }}$ (egg retrieval-1 day; Group A; $\mathrm{n}=97$ ) day of $\mathrm{P}$ administration in the recipients (43). Ongoing pregnancy rates per embryo transfer were similar in all the groups except for a higher biochemical pregnancy rate in group A (12.9\%) when comparing with groups B (6.6\%) and C (2.3\%) (43). In another RCT, when cleavage stage day 3 embryos were warmed and cultured overnight to day 4 , and transferred on the $5^{\text {th }}(\mathrm{n}=150)$ or $3^{\text {rd }}(\mathrm{n}=150)$ day of $\mathrm{P}$ administration, similar CPR's were noted [37/137 (27.0\%) vs. 26/138 (18.8\%) respectively, OR=1.6, 95\% CI $0.9-2.82, \mathrm{p}=0.11]$ (44). However, the early pregnancy loss rate was significantly higher following embryo transfer on the $3^{\text {rd }}$ day of the $\mathrm{P}$ administration group [32/58 (55.2\%) vs 21/58 (36.2\%); $\mathrm{OR}=0.46,95 \%$ CI $0.22-0.97, \mathrm{p}=0.04)]$ (44).

For the blastocyst stage transfer, as mentioned, there are two RCTs; one was presented as an abstract (46) and one was published in a peer review journal (45). In the study by Ding et al., frozen/thawed blastocysts were transferred on the $6^{\text {th }}$ $(\mathrm{n}=23)$ or $7^{\text {th }}$ day $(\mathrm{n}=26)$ of $\mathrm{P}$ administration and a higher $\mathrm{CPR}, \mathrm{OPR}$ and implantation rate was reported in the day 6 group (60.9\% vs $53.8 \%, 56.5 \%$ vs $50.0 \%$ and $40.7 \%$ vs $30.0 \%$, respectively), but the differences did not reach statistical significance ( $p>0.05)$ (46). Moreover, a recent RCT compared the outcomes of blastocyst transfer on the $5^{\text {th }}(n=151)$ or $7^{\text {th }}$ $(n=152)$ day of $\mathrm{P}$ administration and in that study LBRs tended to be in favor of the $5^{\text {th }}$ day of $\mathrm{P}$ administration, although not reaching statistical significance $(31.1 \%$ vs $25.7 \%$, OR $=0.76,95 \%$ CI 0.46 - 1.26) (45). The same group, in a recent retrospective cohort study, compared the reproductive outcome of day-5 and day- 6 vitrified blastocysts transferred on the $6^{\text {th }}(n=346)$ or $7^{\text {th }}$ $(n=273)$ day of P start (47). Although the pooled day-5 and day- 6 blastocysts had comparable LBRs when transferred on the $6^{\text {th }}$ or $7^{\text {th }} \mathrm{P}$ start day (36.6\% for both groups), of interest, a subgroup analysis revealed that day- 6 blastocysts had an insignificantly higher LBRs when transferred on the $7^{\text {th }}$ day of $\mathrm{P}(35.5 \%$ vs $21.5 \%, \mathrm{p}=0.06$ ); the higher LBR was mainly caused by a lower miscarriage rate when transferred on the $7^{\text {th }}$ day of $\mathrm{P}(21.4 \% v s$ $50.0 \%, \mathrm{p}=0.02)$. Although the retrospective study design and subgroup analysis could be considered a limitation of the study the finding of an increase in LBR by delaying transfer of day- 6 blastocysts for one day ( $7^{\text {th }}$ day of $\mathrm{P}$ start) is contrasted by common practice in which day- 6 blastocysts are transferred on the same day as day 5 blastocysts $\left(6^{\text {th }}\right.$ day of $\mathrm{P}$ start). A future RCT exploring this issue is clearly warranted to draw firm conclusions.

In conclusion, limited evidence suggests that, for the optimal length of $\mathrm{P}$ exposure before FET, Day-3 embryos should be transferred on the $3^{\text {rd }}$ or $4^{\text {th }}$ day of $\mathrm{P}$ administration and Day-5/6 blastocysts on the $5^{\text {th }}$ or $6^{\text {th }}$ day of $\mathrm{P}$ administration (Figure 1). A higher LBR for Day 6 vitrified blastocysts when transferred on the $7^{\text {th }}$ day of $\mathrm{P}$ administration, as reported by a single retrospective study, should be warranted by further RCTs.

\section{Natural Cycle (NC)}

Both t-NC and modified-NC is most optimally performed in patients with regular menstrual cycles. In t-NC, to schedule FET, the timing of spontaneous ovulation needs to be precisely pinpointed, necessitating frequent endocrine and transvaginal ultrasonographic monitoring. Hence, NC is less flexible when compared with HRT and modified-NC. In modified-NC, 


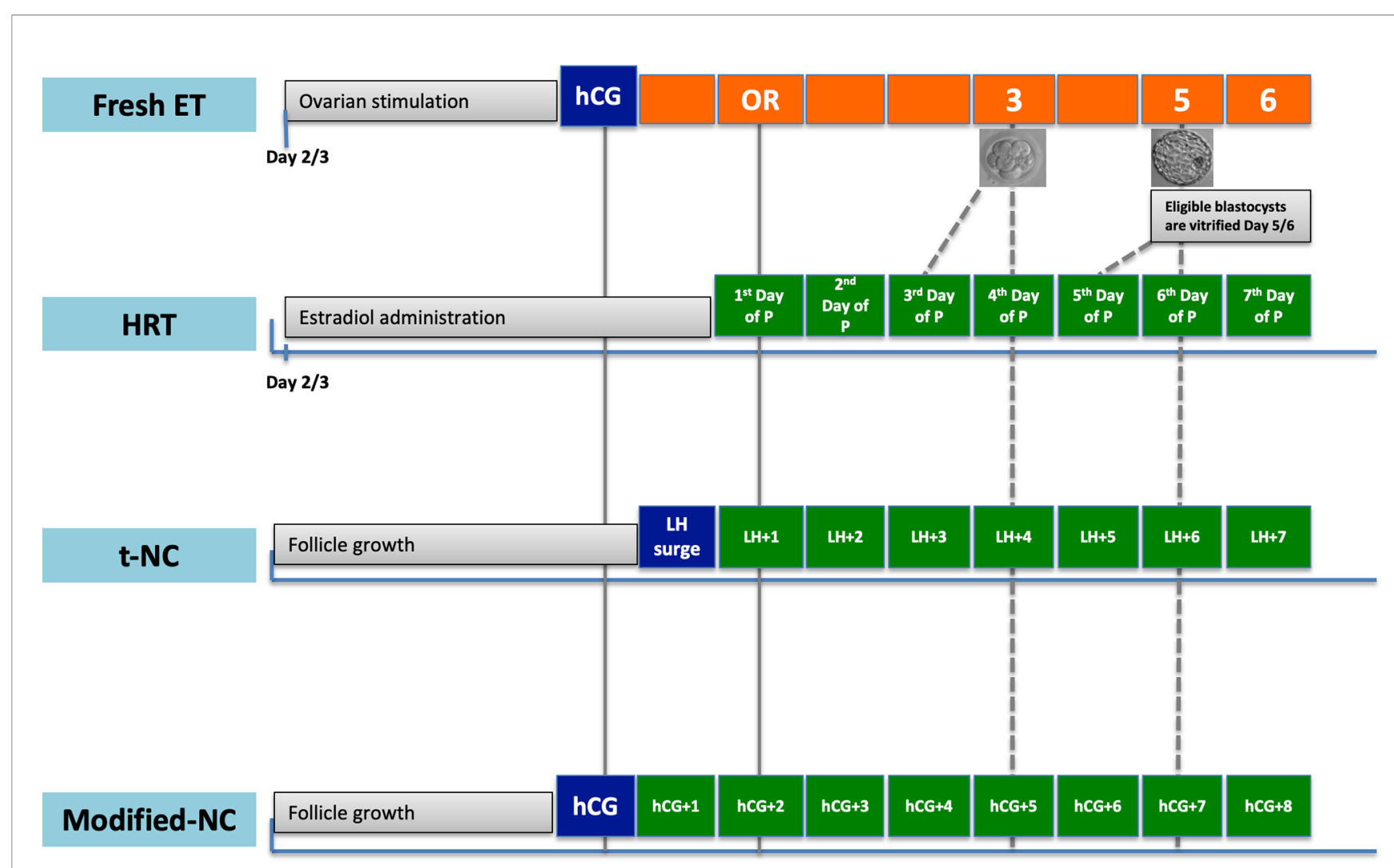

FIGURE 1 | Timing of warmed embryo transfer in hormone replacement treatment (HRT), true natural cycle (t-NC) and modified natural cycle (modified-NC) protocols to prime endometrium. hCG, human chorionic gonadotropin; ET, embryo transfer; P, progesterone; OR, oocyte retrieval; LH, luteinizing hormone. The dash-lines denote timing of warmed embryo transfer in different FET protocols.

triggering is performed when the leading follicle is between 16$20 \mathrm{~mm}$ in diameter and scheduling is performed accordingly; modified-NC requires less endocrine and ultrasonographic monitoring when compared with t-NC and, thus, is considered more patient-friendly.

\section{True-NC (t-NC)}

For t-NC, transvaginal ultrasonography is performed on day 2 or 3 of menses to rule out any cyst or corpus luteum prevailing from the previous cycle. Cycle cancellation is usually undertaken in cycles with serum $\mathrm{P}_{4}>1.5 \mathrm{ng} / \mathrm{ml}$ on day 2 or 3 of menses, even though this practice has been extrapolated from fresh embryo transfer cycles $(48,49)$. To our knowledge, there is no study evaluating the impact of day $2 / 3$ serum $\mathrm{P}_{4}$ on success rates in $\mathrm{t}$ NC, modified-NC, and mild-OS cycles. Transvaginal ultrasonographic monitoring is usually started on day 8-10 and endocrine monitoring is performed, using serum $\mathrm{E}_{2}, \mathrm{LH}$ and $\mathrm{P}_{4}$ measurements when the leading follicle attains a mean diameter of approximately $15 \mathrm{~mm}$ in diameter. Following frequent endocrine and ultrasonographic monitoring, on alternate days or daily, the day of ovulation is precisely documented to schedule the timing of FET.

The place for endocrine monitoring in t-NC is controversial. Thus, a retrospective study of 610 patients undergoing t-NC FET reported a $28.4 \%$ incidence of serum $\mathrm{P}_{4}$ elevation $(>5 \mathrm{nmol} / \mathrm{l}$ ) before the LH surge (50). No significant difference was noted in OPR $(32.5 \%$ vs $31.7 \%)$ of those patients with or without $\mathrm{P}_{4}$ elevation on the day of $\mathrm{LH}$ surge (50). However, if $\mathrm{P}_{4}$ elevation lasted for 2 days, there was a significant reduction in the CPR (39.4\% vs 20.7\%, p=0.04). A subgroup analysis of that study suggested that, not the level, but the duration of $\mathrm{P}_{4}$ exposure before the LH surge was associated with the lower pregnancy rates $(50)$.

\section{Modified-NC}

For modified-NC, the initial monitoring is the same as in t-NC; however, ovulation is triggered with hCG once the leading follicle reaches a mean diameter of 16-20 mm. In modified-NC, hCG, not only induces ovulation, but also results in increased serum $\mathrm{P}_{4}$ production during the early and mid-luteal phase, thus, the hCG trigger works as an ovulation trigger as well as an early LPS. To our knowledge, there is no study comparing different doses of hCG for triggering in modified-NC; in theory, the lowest effective dose to induce ovulation will result in a lower early serum $\mathrm{P}_{4}$, which should reduce the risk of endometrial advancement, known to have a negative impact on endometrial receptivity. The place for endocrine monitoring in modified-NC is controversial $(51,52)$. Whether monitoring of serum $\mathrm{P}_{4}$ and LH levels in modified-NC FET cycles has added clinical value needs to be explored. 


\section{How to Pinpoint the Day of Ovulation in t-NC?}

Pinpointing the day of ovulation is of crucial importance in t-NC and will rely on documenting the LH surge and/or ultrasonographic signs of ovulation. The LH surge should be tested in serum rather than urine since urinary LH testing, with detection limits of 20-40 IU/L, is associated with high falsenegative results (53). Moreover, with urinary testing when compared with serum testing, one-day delay should be taken into account for timing of FET due to urinary clearance of $\mathrm{LH}$ (54-56).

In the $\mathrm{NC}$, the $\mathrm{E}_{2}$ synthesis increases progressively from the dominant follicle and triggers the $\mathrm{LH}$ surge. Prior to the $\mathrm{LH}$ surge, a small increase in $\mathrm{P}_{4}$ level is encountered, which reflects the increasing LH pulse amplitude and frequency leading up to the surge (57). Different cut-off points have been described to define the LH surge; even different criteria may be employed in the same clinic (58). Most commonly, a rise of at least $80 \%$ above the latest serum $\mathrm{LH}$ level with a continued rise, thereafter, is defined as a surge of $\operatorname{LH}(54,59)$. A drop in serum $\mathrm{E}_{2}$ follows the initiation of LH surge due to luteinization of granulosa cells and synthesis of $\mathrm{P}_{4}$ by rising $\mathrm{LH}$ levels. Another suggested definition is the first attainment of $\mathrm{LH} \geq 17$ IU/L during the follicular phase with $\mathrm{a} \geq 30 \%$ drop in $\mathrm{E}_{2}$ levels, the following day (58). The highest serum LH level obtained (usually a day after $\mathrm{LH} \geq 17 \mathrm{IU} / \mathrm{L}$ ) has been considered by others to be the day of LH surge (58). Moreover, a serum LH $>10$ IU/L has also been described to define the LH surge (51). Clearly, this heterogeneity in definition may result in differences in timing of FET which may have impact on reproductive outcomes (58). Irrespective of the definition, a concomitant rise in serum $\mathrm{P}_{4}(>1.5 \mathrm{ng} / \mathrm{ml})$ the day after the LH surge, should be seen to confirm ovulation.

For timing of FET, some clinics, in addition to documentation of the LH surge, also use ultrasonographic signs of ovulation. This may be of some relevance since, although ovulation usually occurs $24 \mathrm{~h}$ after the spontaneous LH surge, it may occasionally occur up to $56 \mathrm{~h}$ after the LH surge (60). Further, follicular collapse is the most common sign of ovulation (61). Not infrequently ( $8 \%$ in our experience-unpublished data), corpus luteum formation, without follicular collapse (luteinized unruptured follicle syndrome (LUF)) may be noted (62); of importance, serum $\mathrm{P}_{4}$ is significantly lower in such LUF cycles when compared to those with follicular rupture despite similar duration of luteal phase $(62,63)$. Clearly, such sub-optimal midluteal serum $\mathrm{P}_{4}$ levels, if not monitored, may be associated with worse reproductive outcome.

To conclude, in t-NC cycle, differences in definition of $\mathrm{LH}$ surge may result in differences in timing of FET which may have impact on reproductive outcomes. The optimal definition of $\mathrm{LH}$ surge associated with the best reproductive outcome should be explored.

\section{Comparison of t-NC Versus Modified-NC}

Three RCTs compare the reproductive outcomes of $\mathrm{t}-\mathrm{NC}$ with modified-NC. The initial RCT with a limited sample size in patients undergoing cleavage stage FET, reported similar CPR and LBR when comparing $\mathrm{t}-\mathrm{NC}(\mathrm{n}=30)$ to modified-NC $(\mathrm{n}=25)$ (64). The second RCT by Fatemi et al. in patients undergoing cleavage stage FET revealed significantly lower OPR with modified-NC $(n=63)$ when compared to t-NC $(n=61) \quad(14.3 \%$ vs $31.1 \%, \mathrm{p}=0.025$, respectively) (65). The timing of FET was the same in both groups, i.e., following overnight culture 5 days after the LH surge or hCG administration (65). No LPS was administered in both groups. Of note, if hCG was administered at the time of an impending $\mathrm{LH}$ surge (without $\mathrm{P}_{4}$ rise), which was encountered in $36.5 \%(23 / 63)$ of the patients, the OPR was disappointingly low $(1 / 23 ; 4.3 \%)$. The study was interrupted prematurely. However, the impact of an impending LH surge on reproductive outcomes in modified-NC is controversial, some reporting a negative impact (66) and others no impact at all $(51,52)$.

A subsequent retrospective study compared $\mathrm{t}-\mathrm{NC}$ without LPS $(\mathrm{n}=501), \mathrm{t}-\mathrm{NC}$ with LPS $(\mathrm{n}=828)$ and modified-NC with LPS $(n=1024)$ (67). There were several differences between this retrospective study and the RCT by Fatemi et al. (65). First, the timing of FET; since ovulation usually occurs at a later stage after hCG administration ( +2 days) compared to ovulation after the spontaneous $\mathrm{LH}$ rise (+1 day) (68), warmed blastocyst transfer was scheduled to $\mathrm{LH}$ surge +6 days in $\mathrm{t}-\mathrm{NC}$ and $\mathrm{hCG}+7$ days in the modified-NC (67). Second, both cleavage and blastocyst stage FET cycles were included in the study by Montagut et al. (67). Third, no LPS was administered in the Fatemi et al. 's RCT (65). Fourth, patients who were scheduled to have a modified-NC-FET, but subsequently had a spontaneous $\mathrm{LH}$ surge were placed in the $\mathrm{t}$ NC or t-NC + LPS groups, depending on whether LPS was added or not in the study by Montagut et al. (67). Despite these differences, the CPR was significantly higher in the $\mathrm{t}-\mathrm{NC}$ group compared to the modified-NC with LPS (46.9\% vs $29.7 \%$, respectively, $\mathrm{p}<0.001$ ), in line with the previous RCT (65).

The most recent RCT, compared t-NC $(n=130)$ to modifiedNC $(n=130)$ in a total 260 patients undergoing cleavage stage FET (69). None of the patients received LPS, and following overnight culture, FET was performed at $\mathrm{LH}$ surge +5 days in the $\mathrm{t}-\mathrm{NC}$ group and $\mathrm{hCG}+6$ days in the modified-NC group. In patients assigned to modified-NC, a shift to t-NC was carried out if a spontaneous surge was detected; this was encountered in $28.4 \%(37 / 130)$ of the patients. The CPR, which was the primary outcome measure, was comparable between the modified-NC and $\mathrm{t}-\mathrm{NC}$ groups $(27.2 \%$ vs $24.4 \%$, respectively; [relative risk $(\mathrm{RR})=0.90,95 \%$ CI $0.59-1.37, \mathrm{p}=0.61$, respectively]), but with fewer clinic visits for patients undergoing modified-NC (69). The FET timing, shifting to t-NC with impending $\mathrm{LH}$ in patients initially assigned to modified-NC and no LPS administration may account for similar reproductive outcome in both groups. However, these results are in line with the previously published retrospective cohort studies (70-73). The results of the ongoing multicenter RCT (Antarctica-2) comparing t-NC and modifiedNC will add important information to this field (74).

In a recent network meta-analysis of 26 RCTs, no difference in LBR was reported between t-NC and modified-NC FET ( $\mathrm{OR}=1.21,95 \%$ CI $0.81-1.82$, low quality evidence) (75).

\section{Timing of Embryo Transfer in t-NC and Modified-NC}

In a $\mathrm{NC}$, the implantation window ranges between $\mathrm{LH}+7$ to $\mathrm{LH}+11$ (76). A difference in the timing of FET in t-NC versus modified-NC 
could be considered, as ovulation occurs 36-48 h after hCG administration, but could vary from 24 to $56 \mathrm{~h}$ after a spontaneous LH surge (60). The usual practice to perform FET at the blastocyst stage is on $\mathrm{LH}+6$ day in $\mathrm{t}-\mathrm{NC}$ (and/or ultrasonographic documentation of ovulation +5 day) and hCG +7 day in modified-NC. In a recent retrospective study of 453 single euploid blastocyst transfers using the modified-NC, timing of FET was adjusted based on the presence or absence of a spontaneous $\mathrm{LH}$ surge ( $\geq 20 \mathrm{mIU} / \mathrm{mL}$ ) (77). With a documented LH surge, FET was scheduled on hCG+6 day $(\mathrm{n}=205)$, whereas it was scheduled to hCG +7 day in those cycles without an LH surge $(n=248)$. Similar LBRs were reported for the hCG+6 and hCG+7 groups $(61.0 \%$ vs $60.9 \%$, respectively, $\mathrm{p}=0.93$; adjusted $\mathrm{OR}=0.98,95 \% \mathrm{CI}$ 0.67-1.45) (77).

Moreover, a Scandinavian multi-center RCT is currently ongoing to explore the optimum timing for transferring a single frozen-warmed blastocyst in modified-NC, that is, hCG+6 days or hCG+7 days (78). In this study, each group is further assigned to receive LPS or not. A total of 604 patients is planned to be randomized to four arms.

In conclusion, for warmed blastocyst transfer cycles, based on the available evidence, FET should be timed on $\mathrm{LH}+6$ day in $\mathrm{t}-$ $\mathrm{NC}$ and hCG+7 day in modified-NC cycles (Figure $\mathbf{1}$ ).

\section{Is LPS Needed in t-NC or Modified-NC?}

The need for LPS in t-NC or modified-NC remains equivocal. Optimum $\mathrm{P}_{4}$ output from the corpus luteum originating from a mono-follicular spontaneous cycle is crucial for establishing and maintaining an intrauterine pregnancy (79). Until now, there are 2 RCTs evaluating LPS in $\mathrm{t}-\mathrm{NC}$, one with exogenous vaginal $\mathrm{P}$ administration (80) and the other with hCG administration (81). In the study by Bjuresten et al., 435 women undergoing cleavage stage FET, were randomized to either vaginal P (400 mg vaginal micronized P bid) or no LPS (80). Embryo transfer was performed on the $\mathrm{LH}$ surge +3 days and exogenous $\mathrm{P}_{4}$ started in the evening of FET. Administration of LPS was associated with a statistically significant increase in LBR (30 vs 20\%; p = 0.027). In the RCT by Lee et al. (81), 450 women undergoing cleavage stage FET employing the t-NC were randomized to two bolus doses of 1,500 urinary hCG, one on the day of FET and one on FET+ 6 days, and FET was performed on the third day after the LH surge. The OPR at 10-12 weeks of gestational age, which was the primary outcome measure, was comparable among the two groups (81).

In $\mathrm{t}-\mathrm{NC}$, regarding the available retrospective studies some favor LPS (82) whereas others report comparable reproductive outcomes with or without LPS $(67,83,84)$.

Since hCG has a long half-life and a sustained luteotropic effect during the early luteal phase up to 7 days following administration (85), LPS might not be needed in modified-NC $(86,87)$. In line with this two RCTs $(87,88)$, two retrospective studies report comparable reproductive outcomes with or without LPS in modified-NC $(89,90)$.

If administered, the timing of LPS administration in a t-NC or modified-NC seems to be important, as too early $\mathrm{P}$ administration, may induce embryo-endometrium asynchrony, resulting in impaired reproductive outcomes (67). If LPS is administered, based on the available evidence, it seems that the LPS should not be started earlier than LH surge+3 day $(67,80)$.

\section{Mild-Ovarian Stimulation (mild-OS)}

Mild OS with an oral agent (CC or letrozole) and/or exogenous gonadotropins may be used to prime the endometrium for FET. For this purpose, mild OS is performed with $<150$ IU urinary/ recombinant follicle stimulating hormone $(\mathrm{FSH}) /$ day, letrozole at a dose of $2.5-5 \mathrm{mg}$ /day or CC at a dose of 50-100 mg/day, starting on the $2^{\text {nd }}$ or $3^{\text {rd }}$ day of the cycle. The follicular response is monitored by frequent vaginal ultrasonography and/or serum endocrine assessment. Human chorionic gonadotropin is administered when the diameter of the leading follicle is greater than $17 \mathrm{~mm}$, endometrial thickness $\geq 7 \mathrm{~mm}$ and serum $\mathrm{E}_{2}$ level $>150 \mathrm{pg} / \mathrm{ml}$. The timing of the FET is scheduled according to the day of embryo freezing; day-3 embryos are transferred on hCG +5 and day-5/6 embryos are transferred on hCG+7 $(91,92)$.

The rationale for mild OS in regularly cycling women is to improve subtle defects in folliculogenesis and subsequent luteal phase, resulting in a better endometrial milieu for embryo implantation $(91,92)$. In addition, mild-OS avoids the reported risks (e.g. thromboembolic events) associated with exogeneous $\mathrm{E}_{2}$ and $\mathrm{P}$ administration in HRT cycles.

Letrozole is an aromatase inhibitor; it has a half-life of $\sim 2$ days compared to $\sim 2$ weeks of CC (93). Unlike CC, the hypothalamicpituitary-ovarian axis is intact during letrozole use. Letrozole has no negative effect on the endometrium (94).

Although the common clinical practice is to employ LPS in mild-OS cycles for FET, mostly extrapolated from non-IVF OS cycles (95), RCTs are clearly warranted to delineate the place for LPS in mild-OS cycles.

\section{Comparison of Different FET Protocols t-NC/Modified-NC Versus HRT}

In a recent Cochrane meta-analysis with pooled analysis of five RCTs, there was a trend, but not reaching statistical analysis, favoring HRT for CPR (OR=0.79, 95\% CI 0.62 - 1.01; $\mathrm{n}=1249$; studies $=5 ; \mathrm{I}^{2}=60 \%$; very low-quality evidence). Of the included five RCTs, four [three published in peer review journals (96-98) and one abstract (99)] employed modified-NC and the remaining t-NC (published as an abstract) (100). No difference in LBR was noted between $\mathrm{t}-\mathrm{NC} /$ modified-NC and HRT $\left(\mathrm{OR}=0.97,95 \%\right.$ CI $0.74-1.28 ; \mathrm{n}=1285 ;$ studies $=4 ; \mathrm{I}^{2}=0 \%$; very low-quality evidence) (5). For comparison of LBR, of the included four RCTs, three employed modified-NC [all three published in peer review journals (96-98)] and the remaining one t-NC (published as an abstract) (100). Of note, the cycle cancellation rate data was available only in one RCT and it was significantly less with modified-NC when compared with HRT protocol (26.7\% vs 20.4\%; p=0.02) (96). The difference in cancellation rates was ascribed mainly to more cancellation due to insufficient endometrial thickness in HRT-FET when compared with modified-NC-FET (OR=13.9, 95\% CI $4.4-46.7$, $\mathrm{p}<0.01)$. The Antarctica trial reported similar cost for modifiedNC and HRT (96).

Regarding the available retrospective and prospective cohort studies, the majority report similar reproductive outcomes (73, $101-104)$, whereas better $(71,105,106)$ or worse $(107,108)$ outcomes have also been reported with $\mathrm{t}-\mathrm{NC} /$ modified-NC when 
compared to HRT. Importantly, in HRT cycles, the early pregnancy loss rate has been alarmingly high in some reports $(73,109)$.

In a very recent network meta-analysis of 26 RCTs, regarding LBR, HRT ranked as the worst (albeit not reaching statistical significance), when compared with $\mathrm{t}-\mathrm{NC}(\mathrm{OR}=0.85,95 \% \mathrm{CI} 0.48$ $1.49)$ and modified-NC (OR=0.79, 95\% CI $0.56-1.11)$ (75). In the same study, the authors also did a pairwise meta-analysis of 113 observational studies; HRT was associated with a significantly lower LBR when compared with $\mathrm{t}-\mathrm{NC}(\mathrm{OR}=0.81,95 \% \mathrm{CI} 0.70-$ $0.93)$ or modified-NC (OR=0.85, 95\% CI $0.77-0.93)(75)$.

In conclusion, the currently available low-quality evidence points toward the $\mathrm{NC}$ ( $\mathrm{t}-\mathrm{NC} /$ modified-NC) being superior to HRT.

\section{Mild-OS Versus HRT}

In a recent Cochrane meta-analysis, when stimulation with gonadotropins, letrozole or CC was pooled, the CPR was significantly higher with mild-OS when compared to HRT cycles $\left(\mathrm{OR}=1.63,95 \%\right.$ CI $1.12-2.38 ; \mathrm{n}=656$; five RCTs; $\mathrm{I}^{2}=$ $11 \%$; low-quality evidence) (5). In the subgroup analysis, the CPR was significantly higher with letrozole when compared to HRT $\left(\mathrm{OR}=1.94,95 \%\right.$ CI $1.24-3.04 ; \mathrm{n}=365 ; 3$ RCTs; $\mathrm{I}^{2}=15 \%$; low-quality evidence). The LBR was comparable with letrozole and HRT in the only available RCT including a limited sample size $(\mathrm{OR}=1.26,95 \% \mathrm{CI} 0.49$ - 3.26; $\mathrm{n}=100$; one study; very lowquality evidence) $(5,110)$. The CPR was comparable with CC (111) or gonadotropins (112) when compared with HRT with no data on LBR.

In a recent network meta-analysis of 26 RCTs comparing different FET protocols, when compared with HRT, significantly higher LBRs were reported with mild-OS using gonadotropin (OR=1.77, 95\%CI 1.06 - 2.98; very-low quality of evidence) or mild-OS using letrozole (OR=1.67, 95\%CI 1.22 - 2.28; low quality of evidence) (75). However, no significant difference in LBR was noted between t-NC, modified-NC and mild-OS protocols (75).

The endometrial thickness was significantly reduced with CC (Mean Difference $=-1.04,95 \%$ CI -1.59 to $-0.49 ; n=92$; one study; low-quality evidence) compared to HRT (5). The endometrial thickness, on the day of starting exogenous $\mathrm{P}$ as well as on the day of FET, was significantly higher in the letrozole group when compared to HRT in a recent retrospective study of 2,664 patients with PCOS undergoing FET (113). However, two other small-scaled studies reported no significant difference in endometrial thickness comparing mild-OS with letrozole to HRT cycles $(110,114)$.

In conclusion, although HRT and $\mathrm{NC}$ ( $\mathrm{t}-\mathrm{NC} /$ modified-NC) are the most commonly used protocols, recent emerging evidence suggests that mild-OS may be a viable option for FET.

\section{INDIVIDUALIZED FET APPROACH}

\section{Endocrine Monitoring}

Personalized medicine is crucial to maximize efficacy, safety and minimize treatment burden, and priming of the endometrium for FET, is obviously not an exception. An optimal exposure of the endometrium to $\mathrm{P}$ in terms of timing and concentration, is essential to maximize the reproductive outcome of the HRT cycle. In theory, the use of endometrial $\mathrm{P}_{4}$ measurements would be ideal, however, this is not feasible in clinical practice, and as such the serum $\mathrm{P}_{4}$ level, which is impacted by the route of administration, is still the best proxy for the endometrial progesterone level (115). Until recently, "im-personalized", standard LPS without luteal serum $\mathrm{P}_{4}$ monitoring was the" standard of care" and the typical practice for HRT cycles in IVF programs. However, recently available evidence clearly indicates that, in HRT cycles, there might be marked inter-personal variation in serum $\mathrm{P}_{4}$ levels with an impact on reproductive outcomes, despite the use of the same dose and route of $\mathrm{P}$ administration (36, 116-128). Although these studies were heterogenous in population, regarding the type, dose, and mode of $\mathrm{P}$ administration, of the embryo stage at transfer, and the day of serum $\mathrm{P}_{4}$ measurement, better reproductive outcomes were reported when the serum $\mathrm{P}_{4}$ level was above a certain threshold, ranging from 8.75 to $32.50 \mathrm{ng} / \mathrm{ml}(36,116-120,122-$ 124, 126, 127) (Table 2).

It remains to be determined whether a ceiling level of serum $\mathrm{P}_{4}$ in HRT cycles exists above which reproductive outcomes are impaired. A ceiling effect was reported in three HRT studies (121, $124,126)$, whereas no significant effect was reported in the remaining $8(36,116-120,122,127)$.

In the Kofinas et al.'s study, including 213 patients undergoing euploid blastocyst transfer and HRT with im P, a ceiling effect was reported with serum $\mathrm{P}_{4}$ levels over $20 \mathrm{ng} / \mathrm{ml}$ on the sixth day of $\mathrm{P}$ start (121). In the Yovich et al. study, using a homemade pessary, an optimal serum $\mathrm{P}_{4}$ window of 22.01-31.1 $\mathrm{ng} / \mathrm{ml}$ on the sixth day of $\mathrm{P}$ start was reported, whereas patients with serum $\mathrm{P}_{4}$ levels exceeding $31.1 \mathrm{ng} / \mathrm{ml}$ had poorer implantation rates and LBRs $(124)(n=539)$. In a very recent study, a ceiling effect was noted for CPR and LBR with serum $\mathrm{P}_{4}$ levels $\geq 32.5 \mathrm{ng} / \mathrm{ml}$ (126). In our recent study of 475 FET cycles, no ceiling effect was noted on OPR in either the vaginal gel only or vaginal gel and im P supplemented groups (36).

Since a corpus luteum is absent in HRT-FET, the marked interpersonal differences in serum $\mathrm{P}_{4}$ might be caused by altered pharmacokinetics (uptake/distribution and metabolism) of the exogenous $\mathrm{P}$ (129), affected by body mass index (BMI) $(118,125)$, female age $(125,130)$, as well other intrinsic patient factors $(125)$.

Unlike serum $\mathrm{P}_{4}$, no association has been noted between lateproliferative phase serum $\mathrm{E}_{2}$ levels and LBR in HRT cycles (131).

\section{Rescue Protocol}

A natural question to ask regarding patients with low serum $\mathrm{P}_{4}$ levels, is whether the cycle can be "rescued" with additional exogenous $\mathrm{P}$, using the same or a different route of administration. In an oocyte donation study by Brady et al. ( $\mathrm{n}=229$ cycles), im $\mathrm{P}$ was administered at a dose of 50-100 mg per day, commencing in the evening and 4 days before cleavage stage embryo transfer (118). Serum $\mathrm{P}_{4}$ was measured on the day of embryo transfer and if $\mathrm{P}$ was $<20 \mathrm{ng} / \mathrm{mL}$, the dose of im $\mathrm{P}$ was increased by $50-100 \%$. The threshold of $20 \mathrm{ng} / \mathrm{ml}$ represented the cut-off value between the first and second tertiles of serum $\mathrm{P}_{4}$ on the day of embryo transfer. Additional P dosing was necessary in a total of $32.8 \%$ of the cycles (75 of 229). However, despite supplementation, the LBR was still lower compared to patients with serum $\mathrm{P}_{4}>20 \mathrm{ng} / \mathrm{ml}$ (52.0\% vs 64.9\%, $\left.\mathrm{p}=0.04\right)$ (118). 
TABLE 2 | Overview of studies on serum progesterone (P) monitoring in HRT cycles.

\begin{tabular}{|c|c|c|c|c|c|c|}
\hline Reference & $\mathbf{n}$ & $\begin{array}{l}\text { Route } \\
\text { of } P\end{array}$ & Dose of $P$ & $\begin{array}{c}\text { Optimal P level/P test } \\
\text { day }\end{array}$ & Site/No. of embryo transfer/embryos & $\begin{array}{l}\text { Outcome, \% (high } \\
\text { vs low P group) }\end{array}$ \\
\hline $\begin{array}{l}\text { Brady et al., } 2014 \\
(118)\end{array}$ & 229 & $\mathrm{im}$ & $50-100 \mathrm{mg} \times 1$ & $\begin{array}{l}>20 \mathrm{ng} / \mathrm{ml}(64 \mathrm{nmol} / \mathrm{l}) / 5^{\text {th }} \\
\mathrm{P} \text { day }\end{array}$ & Single center/ 1 to $>3$ fresh donor Day 3 embryos & LBR (65 vs 51) \\
\hline $\begin{array}{l}\text { Kofinas et al., } \\
2015^{\mathrm{a}}(121)\end{array}$ & 213 & $\mathrm{im}$ & $50-75 \mathrm{mg} \times 1$ & $\begin{array}{l}<20 \mathrm{ng} / \mathrm{ml}(64 \mathrm{nmol} / \mathrm{l}) / 6^{\text {th }} \\
\mathrm{P} \text { day }\end{array}$ & $\begin{array}{l}\text { Single center/SET/vitrification, euploid blastocyst, } \\
\text { autologous }\end{array}$ & LBR (65 vs 49) \\
\hline $\begin{array}{l}\text { Yovich et al., } 2015^{a} \\
(124)\end{array}$ & 529 & Vaginal & $\begin{array}{l}400 \mathrm{mg} \times 3 \text { (in-house } \\
\text { produced pessaries) }\end{array}$ & $\begin{array}{l}22.1-31.2 \mathrm{ng} / \mathrm{ml}(70- \\
99 \mathrm{nmol} / \mathrm{l} / 6^{\text {th }} \mathrm{P} \text { day }\end{array}$ & $\begin{array}{l}\text { Single center/SET/vitrification, blastocyst, } \\
\text { autologous + donor }\end{array}$ & LBR (50 vs 41) \\
\hline $\begin{array}{l}\text { Labarta et al., } 2017 \\
\text { (122) }\end{array}$ & 211 & Vaginal & $400 \mathrm{mg} \times 2$ (micronized P) & $\begin{array}{l}>11 \mathrm{ng} / \mathrm{ml}(>35 \mathrm{nmol} / \mathrm{l}) / \\
6^{\text {th }} \mathrm{P} \text { day }\end{array}$ & $\begin{array}{l}\text { Single center/SET or DET/vitrification, blastocyst, } \\
\text { donor }\end{array}$ & OPR (53 vs 43) \\
\hline $\begin{array}{l}\text { Basnayake et al., } \\
2018(117)\end{array}$ & 1580 & Vaginal & Various & $\begin{array}{l}>15.8 \mathrm{ng} / \mathrm{ml}(>50 \mathrm{nmol} / \\
\text { l) } / 6^{\text {th }} \mathrm{P} \text { day }\end{array}$ & $\begin{array}{l}\text { Multicenter/SET/cleavage or blastocyst, slow } \\
\text { freeze or vitrification, donor + autologous }\end{array}$ & LBR (27 vs 11) \\
\hline $\begin{array}{l}\text { Alsbjerg et al., } \\
2018 \text { (116) }\end{array}$ & 244 & Vaginal & $\begin{array}{l}90 \text { mg } \times 3 \text { (bioadhesive } \\
\text { P gel) }\end{array}$ & $\begin{array}{l}\geq 11 \mathrm{ng} / \mathrm{ml}(\geq 35 \mathrm{nmol} / \mathrm{l}) / \\
9^{\text {th }}-11^{\text {th }} \mathrm{P} \text { day }\end{array}$ & $\begin{array}{l}\text { Single center/SET or DET/blastocyst, vitrification, } \\
\text { autologous }\end{array}$ & OPR (51 vs 38) \\
\hline $\begin{array}{l}\text { Gaggiotti-Marre et } \\
\text { al., } 2019(120)\end{array}$ & 244 & Vaginal & $200 \mathrm{mg} \times 2$ (micronized P) & $>10.64 \mathrm{ng} / \mathrm{ml} / 4^{\text {th }} \mathrm{P}$ day & $\begin{array}{l}\text { Single center/preferably SET/vitrification, euploid } \\
\text { blastocyst, autologous }\end{array}$ & LBR (62 vs 48) \\
\hline $\begin{array}{l}\text { Cédrin-Durnerin et } \\
\text { al., } 2019 \text { (119) }\end{array}$ & 227 & Vaginal & $200 \mathrm{mg} \times 2$ (micronized P) & $\begin{array}{l}\geq 10 \mathrm{ng} / \mathrm{ml} / 2^{\text {nd }}, 3^{\text {rd }} \text { or } 5^{\text {th }} \\
\text { P Day }\end{array}$ & $\begin{array}{l}\text { Single center/SET or DET/Day } 2 \text { or } 3 \text { or } \\
\text { blastocyst, autologous }\end{array}$ & LBR (31 vs 17) \\
\hline $\begin{array}{l}\text { Boynukalin et al., } \\
2019(127)\end{array}$ & 168 & $\mathrm{im}$ & 100 mg/daily & $\geq 20.6 \mathrm{ng} / \mathrm{ml} / 6^{\text {th }} P$ day & $\begin{array}{l}\text { Single center/Single euploid blastocyst transfer/ } \\
\text { Day5 biopsied blastocysts, vitrification }\end{array}$ & OPR (70 vs 42) \\
\hline $\begin{array}{l}\text { Polat et al., } 2020 \\
\text { (36) }\end{array}$ & 143 & Vaginal & $\begin{array}{l}90 \text { mg } \times 2 \text { (bioadhesive } \\
\text { P gel) }\end{array}$ & $>8.75 \mathrm{ng} / \mathrm{ml} / 5^{\text {th }} \mathrm{P}$ day & Single center/SET or DET/vitrification, blastocyst & OPR (47 vs 29) \\
\hline $\begin{array}{l}\text { Alyasin et al., 202/ } \\
(126)\end{array}$ & 258 & $\begin{array}{l}\text { Vaginal } \\
\text { and im }\end{array}$ & $\begin{array}{l}400 \mathrm{mg} \times 3 \text { (micronized P) } \\
\text { and } 50 \mathrm{mg} / \text { daily/im }\end{array}$ & $<32.5 \mathrm{ng} / \mathrm{ml} / 5^{\text {th }} \mathrm{P}$ day & Single center/SET or DET/vitrification, blastocyst & LBR (42 vs 23) \\
\hline
\end{tabular}

${ }^{a}$ study reporting detrimental effect of high progesterone level on reproductive outcome.

P, Progesterone; SET, Single embryo transfer; DET, Double embryo transfer; LBR, Live Birth Rate; OPR, Ongoing Pregnancy Rate; im, intramuscular.

In the study by Cedrin-Durnerin et al., a total of 195 patients undergoing 227 FET cycles in an HRT protocol were included (119). Micronized vaginal P, $200 \mathrm{mg}$ three times daily was used for LPS. Embryo transfer was performed after the morning administration of $\mathrm{P}$, on day 2 of $\mathrm{P}$ administration for day 2 embryos, on day 3 for day 3 embryos and on day 5 for blastocysts. Serum $\mathrm{P}_{4}$ was measured immediately before embryo transfer in all patients. If the serum $\mathrm{P}_{4}$ level was less than $10 \mathrm{ng} / \mathrm{ml}$ ( $\mathrm{n}=85$ patients), patients were contacted in the afternoon to increase the $\mathrm{P}$ dose to $400 \mathrm{mg}$ three times daily and a new blood sample was performed two days later to check the serum $\mathrm{P}_{4}$ level. The repeat serum $\mathrm{P}$ level two days later, available in 80 patients, showed an increase in serum $\mathrm{P}_{4}$ level $>10 \mathrm{ng} / \mathrm{ml}$ in 55 (69\%) patients, only. However, the LBR in patients who had increased serum $\mathrm{P}_{4}$ levels of $>10 \mathrm{ng} / \mathrm{ml}$ after increased dosing were not statistically different from those in whom serum $\mathrm{P}_{4}$ levels remained $<10 \mathrm{ng} / \mathrm{ml}$ ( $20 \%$ and $12 \%$, respectively). Moreover, the LBR of this group of patients was overall lower than in patients with serum $\mathrm{P}_{4}>10 \mathrm{ng} / \mathrm{ml}$ group who did not require supplementation (119).

Notwithstanding the above findings, these two studies have several limitations $(118,119)$. First, both studies were retrospective with inherent selection bias. Second, LPS "rescue" was not the main research question in the studies $(118,119)$, and without performing multivariate logistic regression analysis, it is not possible to accept or refute the role of rescue in these cycles. Third, even with the rescue protocol, the lowest serum $\mathrm{P}_{4}$ level below which cycle cancellation was undertaken was not reported in the available two studies $(118,119)$.

In a very recent prospective cohort study, the impact of rescue on the reproductive outcome was evaluated in 453 women undergoing
574 euploid blastocyst transfer in an HRT protocol (128). For serum $\mathrm{P}_{4}$, a cut-off point of $10.6 \mathrm{ng} / \mathrm{ml}$, one day prior to embryo transfer, was taken as the threshold below which rescue was performed by administering a supplementary dose of $25 \mathrm{mg}$ sc P. Cycles with serum $\mathrm{P}_{4}>10.6 \mathrm{ng} / \mathrm{ml}$ served as the controls $(\mathrm{n}=348)$. Of the 574 cycles included, rescue was necessary in a total of 226 cycles (39.4\%). Embryo transfer was performed if serum $\mathrm{P}_{4}$ levels exceeded $10.6 \mathrm{ng} /$ $\mathrm{ml}$ on the day of FET (one day after rescue) which was the case in 98.2\% of cycles. The LBRs of the control and rescue groups were comparable (49.1\% vs 52.3\%: respectively, RD -3.2\%, 95\% CI - 12; 5.7). Moreover, no significant difference was noted in the miscarriage rate (12.4\% vs $9.2 \%$, respectively; $\mathrm{RD}=3.2 \%, 95 \% \mathrm{CI}-4.3 ; 10.7)$ (128).

We recently reported rectifying OPRs with a rescue protocol in patients undergoing HRT FET and low serum $\mathrm{P}_{4}$ concentrations one day prior to FET (132) Vaginal bioadhesive gel $90 \mathrm{mg}$ bid was used for LPS. Employing a case-control study design, 40 patients with low serum $\mathrm{P}_{4}$ concentrations $(<8.75 \mathrm{ng} /$ $\mathrm{ml}$ ) on the $5^{\text {th }}$ day of $\mathrm{P}$ supplementation underwent rescue with a daily bolus of $25 \mathrm{mg}$ s.c. $\mathrm{P}$, starting on the afternoon of the $5^{\text {th }}$ day of $\mathrm{P}$ administration. For every patient who underwent $\mathrm{P}$ rescue, three patients matched by age, body mass index, number of previous attempts and number of blastocysts transferred, with serum $\mathrm{P}_{4}$ concentration $>8.75 \mathrm{ng} / \mathrm{ml}$ on the $5^{\text {th }}$ day of $\mathrm{P}$ administration served as controls $(n=120)$. Following rescue, the mean serum $\mathrm{P}_{4}$ concentration on the day of vitrified-warmed embryo transfer ( $6^{\text {th }}$ day of $\mathrm{P}$ administration) was rectified in all patients and was $33.43 \pm 10.83 \mathrm{ng} / \mathrm{ml}$ (range 14.61-82.64 ng/ml). The OPR of the rescue and control groups were comparable (50\% vs. $48.3 \%, \mathrm{p}=0.853$, respectively) (132).

It is reassuring that the study by Alvarez et al. (128) and ours (132), the first two studies of its kind, are concordant and 
support rectifying reproductive outcome by a rescue protocol of a daily bolus of $25 \mathrm{mg}$ s.c. P, starting on the afternoon of the $5^{\text {th }}$ day of $\mathrm{P}$ administration. However, some differences between two studies still exist: i) type of vaginal $\mathrm{P}$ used: micronized vaginal $\mathrm{P}$ at a dose of $200 \mathrm{mg} / 8$ hours in the study by Alvarez et al. and vaginal bioadhesive gel $90 \mathrm{mg} / 12$ hours in our study; ii) no fixed timing for $\mathrm{P}$ (vaginal/sc P) administration and blood withdrawal in the study by Alvarez et al. in contrast to 4-5 hours after morning administration of vaginal gel in our study; iii) FET was scheduled on P start+6 day in both studies; however, in the study by Alvarez et al., the nightly administration of P (200 mg) was the dose for the first day of $\mathrm{P}$ administration. Hence, the patients apparently did not receive the full dose of $200 \mathrm{mg} / 8 \mathrm{hr}$ on the first day of $\mathrm{P}$ administration; iv) minimum $\mathrm{P}_{4}$ level below which cycle cancellation was undertaken: it was not reported in the study by Alvarez et al. but was set as $4 \mathrm{ng} / \mathrm{ml}$ (albeit arbitrary) on the $5^{\text {th }}$ day of P start, in our study; v) the threshold of $10.6 \mathrm{ng} / \mathrm{ml}$ in their study is the interception of second and third quartiles (120), whereas, our threshold of $8.75 \mathrm{ng} / \mathrm{ml}$ was the $10 \%$ of our previous study (36).

Further RCTs are warranted, exploring different types and routes of $\mathrm{P}$ to firmly establish the success of the rescue protocol. Finally, the lowest serum $\mathrm{P}_{4}$ level suitable for rescue should also be defined.

Using a threshold of $10 \mathrm{ng} / \mathrm{ml}$ during the mid-luteal phase of natural cycles (133), a luteal phase defect was reported in $8 \%$ of normo-ovulatory subfertile women (134). To our knowledge, until now, only one study reported the impact of serum $\mathrm{P}_{4}$ one day prior to warmed blastocyst transfer in t-NC cycles (135). In this study, a total of $294 \mathrm{t}-\mathrm{NC}$ FET cycles, were included; of those 294 cycles a total of $86(29.2 \%)$ were PGT-A cycles. No LPS was administered. Patients were divided into two groups according to serum $\mathrm{P}_{4}$ levels, below or above $10 \mathrm{ng} / \mathrm{ml}$ on the day before FET. Of note, $37 \%$ patients had a serum $\mathrm{P}_{4}$ level $<10 \mathrm{ng} / \mathrm{ml}$. Patients in the higher $\mathrm{P}_{4}$ group $(>10 \mathrm{ng} / \mathrm{ml})$ had higher CPR $(48.6 \%$ vs 33.0\%: $\mathrm{RD}=15.6 \%, 95 \% \mathrm{CI} 4-27)$ and LBR (41.1\% vs $25.7 \%$ : risk difference $(\mathrm{RD})=15.4 \%, 95 \%$ CI 5-26) than those with $\mathrm{P}_{4}$ levels $<10 \mathrm{ng} / \mathrm{ml}$. Of note, patients with serum $\mathrm{P}_{4}$ levels $<10 \mathrm{ng} / \mathrm{ml}$ on the day before FET had a significantly higher weight and BMI compared to patients with serum $\mathrm{P}_{4}$ levels $>10 \mathrm{ng} / \mathrm{ml}$, and obviously the pulsatile secretion of $\mathrm{P}_{4}$ is a limitation of one single measurement. Whether cycle cancellation or rescue with $\mathrm{P}$ should be undertaken in cycles with low serum $\mathrm{P}_{4}$ needs to be further evaluated.

\section{Assessment of Window of Implantation (WOI)}

Despite the transfer of good quality blastocysts, implantation failure due to an endometrial factor still remains a challenge for both physicians and embryologists. The endometrium is receptive during the window of implantation (WOI) regulated by an incompletely understood endocrine, paracrine, and autocrine factors (136). During the natural cycle, the WOI is limited to days 8-10 after ovulation during which the blastocyst may implant (137). However, there seems to be marked interpersonal differences in the timing of the WOI that cannot be elucidated by ultrasonographic, hormonal or histologic assessments (138). Recently, a commercial endometrial receptivity array (ERA) test was brought to the market as a new tool to define the WOI, particularly in patients with recurrent implantation failure, permitting personalized timing of the embryo transfer (pET). Of interest, 12\% of good prognosis patients (normal ovarian reserve and at least 6 mature oocytes retrieved) have been reported to have an altered WOI (139). The ERA test evaluates the 238 transcriptomic signature genes in a timely sampled endometrial tissue by a machine learning algorithm to identify the endometrial sample's receptivity status on the day of biopsy (140).

In this aspect, a recently published multicenter, open-label RCT explored pET policy in 458 good prognosis women (female age $\leq$ body-mass index of $18.5-30.0 \mathrm{~kg} / \mathrm{m}^{2}$, antral follicle count $\geq 8$ and FSH $<8 \mathrm{IU} / \mathrm{L}$ ) undergoing blastocyst transfer (141). Patients were randomized to pET guided by ERA $(n=148)$, FET $(n=154)$ or fresh embryo transfer $(n=156)$ in 16 clinics. Although reproductive outcomes by intention-to-treat analysis were comparable, the cumulative LBRs after 12 months were $71.2 \%$ in pET versus $55.4 \%$ in FET $(\mathrm{p}=0.04$ ), and $48.9 \%$ in fresh embryo transfer $(\mathrm{p}=0.003)$ groups. Clinical pregnancy rates after the first embryo transfer were higher with pET compared with FET $(72.5 \%$ vs $54.3 \%$, respectively, $\mathrm{p}=0.01)$ and fresh embryo transfer $(72.5 \%$ vs $58.5 \%$, respectively; $\mathrm{p}=0.05)$ groups.

Until now, however, the place of ERA testing in FET cycles is controversial as three recent studies refuted any potential benefit of ERA testing (142-144) whereas one study reported more favorable outcomes, however, not reaching statistical significance (145). In the study by Riestenberg et al, a total of 228 single euploid FET HRT cycles were either guided by ERA testing (pET) $(n=147)$ or by standard timing without ERA $(\mathrm{n}=81)(144)$. The LBR did not differ between patients who underwent FET with ERA/pET, 45/81 (56.6\%) or standard timing 83/147 (56.5\%) (144).

In conclusion, the available data on ERA testing for personalized timing of embryo transfer are conflicting and warrant further studies.

\section{Endometrial Thickness and Thin Endometrium}

An endometrial thickness of $7 \mathrm{~mm}$ is generally considered to be the cut-off for a "thin" endometrium, below which many physicians would cancel an embryo transfer $(146,147)$. In the recent Canadian Database of 12,433 FET cycles, thin endometrium has been reported in $\sim 3 \%$ of the cycles (147); both CPR and LBR decreased significantly when the endometrial thickness was below $7 \mathrm{~mm}$ on the day of P start or documentation of LH surge. The LBRs with endometrial thickness of 5.0-5.9 mm (71 cycles), 6.0-6.9 mm (290 cycles), $7.0-7.9 \mathrm{~mm}$ ( 848 cycles) and $\mathrm{mm}$ (9860 cycles) were $16.9 \%$, $31.7 \%, 33.3 \%$ and $40.6 \%$, respectively. No live birth occurred in nine patients with endometrial thickness $<5 \mathrm{~mm}$ (147).

In contrast to the Canadian database study, a recent smallscaled retrospective study of 287 HRT cycles reported no linear association between endometrial thickness, LBR and miscarriage rate (148). Area under the curve values for endometrial thickness to predict LBR was 0.47 (148).

Thin endometrium remains to be a challenge to overcome. Several strategies have been proposed to manage thin 
endometrium in FET cycles, including modification of $\mathrm{E}_{2}$ use (149-151), in-utero administration of granulocyte colony stimulating factor (152), in-utero administration of plateletrich plasma (153), vaginal sildenafil (154), oral pentoxyfiline, oral tocopherol (155), oral aspirin (156) or pelvic floor neuromuscular electrical stimulation (157). However, none of these strategies have been unequivocally proven to be of benefit in patients with thin endometrium (158).

Three modifications on the administration of $E_{2}$ have been investigated in patients undergoing HRT FET with thin endometrium (158): i) increasing the dose and duration of $E_{2}$ administration. In the only available prospective case-control study, of the 36 patients with a history of refractory thin endometrium and planned to undergo fresh embryo transfer, 23 had fresh embryo transfer despite thin endometrium and the remaining 13 patients had HRT FET with an extended $\mathrm{E}_{2}$ therapy (149). A significant increase in endometrial thickness $(6.7 \pm 0.9 \mathrm{~mm}$ in fresh transfer cycles vs. $8.6 \pm 0.7 \mathrm{~mm}$ in HRT FET cycles; $\mathrm{p}=0.031)$ and CPR $(4.3 \%$ in fresh transfer cycles $v s$. $38.5 \%$ in HRT FET cycles, $\mathrm{p}=0.016$ ) was noted following an extended $\mathrm{E}_{2}$ therapy lasting 14 to 82 days (mean=30 days) (149); ii) changing the route of administration of $E_{2}$. While oral route is widely prescribed due to its simple and well-tolerated use, parenteral routes may increase serum $\mathrm{E}_{2}$ concentration through bypassing the first-pass hepatic metabolism (159). Moreover, vaginal administration of $\mathrm{E}_{2}$ is associated with firstpass uterus effect (160). Thus, in theory, vaginal administration, either alone or combined with oral administration, may be a viable option in patients with thin endometrium. A retrospective study of 247 patients undergoing HRT-FET with thin endometrium compared extended oral $\mathrm{E}_{2}$ administration-only $(n=69)$ with extended oral \& vaginal $E_{2}$ administration (1-2 mg/ day) $(n=178)(150)$. Although extended oral \& vaginal $E_{2}$ administration was associated with a significantly thicker endometrium, CPRs of the two groups were comparable (150). In contrast, an increase in endometrial thickness by supplementing with vaginal $\mathrm{E}_{2}(4 \mathrm{mg} /$ day) was refuted by a prospective trial (161). Subcutaneous $\mathrm{E}_{2}$ pellets may be used for thin endometrium as was reported by a small scaled oocyte donation study (162); iii) modification of the type of $E_{2}$. A RCT compared vaginal synthetic estrogen $(n=30)$ with vaginal natural estrogen $(n=30)$ in patients with refractory thin endometrium. Endometrial thickness in the synthetic $\mathrm{E}_{2}$ group was significantly higher when compared with the natural $\mathrm{E}_{2}$ group (5.93 $\pm 0.38 v s$. $6.74 \pm 0.32$; respectively, $\mathrm{p}<0.001)$ (151); of note, reproductive outcomes have not been reported. Clearly, more well-designed trials are warranted to delineate the role of modification of $\mathrm{E}_{2}$ administration in patients with refractory thin endometrium.

The impact of thin endometrium on reproductive outcome may go beyond the chance of conception since thin endometrium may be associated with adverse obstetric and neonatal outcomes (163, 164). In a very recent study of $13,383 \mathrm{FET}$ cycles (HRT and NC), an increasing risk of preterm delivery and low birth weight has been reported with thin endometrium $(<8 \mathrm{~mm})(164)$.

Recently, in HRT cycles, endometrial compaction, as defined by a decrease in endometrial thickness at the time of warmed blastocyst transfer when compared to the day of $\mathrm{P}$ start, was reported to be a favorable factor for OPR when compared to cycles with no change or increase in endometrial thickness (165, 166). Of note, endometrial compaction was seen in $69 \%$ (187/ 271) HRT-FET cycles (165). The authors suggested that failure of endometrial compaction may be caused by an inadequate response to $\mathrm{P}$ or to $\mathrm{P}$ resistance (167) which may be overcome, in theory, by increasing the dose or duration of $\mathrm{P}$ during the luteal phase and/or decreasing exogenous or endogenous estrogen. The authors further speculated that endometrial compaction may be an important biomarker in fresh, t-NC and modified-NC FET. However, several recent large-scale studies refuted the importance of endometrial compaction in HRT (168-170), modified-NC $(168,169,171)$ and even fresh embryo transfer cycles (172).

In conclusion, endometrial thickness below $7 \mathrm{~mm}(5-7 \mathrm{~mm})$ is a weak predictor of reproductive outcome in FET cycles. However, although rare, very thin endometrium $(<5 \mathrm{~mm})$ is associated with futile outcome. The limited available evidence does not support any particular treatment modality to be of benefit in patients with thin endometrium. Endometrial compaction is not a predictor of reproductive outcome in FET cycles.

\section{FET Cycles in Patients With Endometriosis}

Biological differences exist in eutopic endometrium of patients with and without endometriosis (173-175) which may contribute to altered endometrial receptivity $(176,177)$. In a matched cohort study by Bourdon et al. (178), including a total of 270 endometriosis patients undergoing either fresh embryo or frozen embryo transfer, the authors reported a doubling of the cumulative OPR in patients undergoing FET as compared to fresh transfer (34.8\% vs 17.8\%), clearly showing a benefit of FET in this subgroup of patients $(178,179)$. To our knowledge, there is no RCT comparing different FET protocols in patients affected with endometriosis. An extended gonadotropin suppression therapy of 2 months before the FET-HRT cycle may benefit such patients (180). However, sufficiently powered RCTs are warranted to confirm such a policy.

\section{FET Cycles in Patients With Polycystic Ovary Syndrome (PCOS)}

Mild-OS and HRT are the two most commonly applied FET protocols in patients with PCOS; however, there is no RCT comparing the reproductive outcomes of these two protocols.

In a recent meta-analysis of four retrospective studies, mildOS (letrozole or low dose gonadotropins) was compared with HRT in PCOS patients (181). No significant difference was noted in OPR, 52.1\% with mild-OS and 47.3\% with HRT ( 4 studies, $\mathrm{n}=$ 2,933; OR=1.12, 95\% CI, 0.92-1.35; $\left.\mathrm{I}^{2}=59 \%\right)$. Similarly, LBR, $\mathrm{CPR}$, implantation and miscarriage rates were comparable. However, in a subgroup analysis, a lower miscarriage rate was noted in letrozole-stimulated cycles than HRT cycles ( 3 studies; $\mathrm{OR}=0.53 ; 95 \%$ CI $\left.0.40-0.70 ; \mathrm{I}^{2}=0 \%\right)(181)$. These intriguing findings need to be confirmed by future RCTs. 


\section{MATERNAL AND OBSTETRIC OUTCOMES AFTER DIFFERENT FET PROTOCOLS}

Hypertensive disorders in pregnancy are significantly increased following an HRT cycle compared with NC or mild OS-FET cycle (182-185). The increased risk may relate to the absence of a corpus luteum leading to i) decreased serum relaxin and vascular endothelial growth factor levels ii) lower reactive hyperemia index, iii) lower angiogenic and nonangiogenic circulatory endothelial progenitor cells iv) a lack of drop in mean arterial pressure during pregnancy (186-189). Moreover, the risk of postpartum hemorrhage, and cesarean section is significantly increased after HRT compared with t-NC or modified-NC (182, 183, 185). Macrosomia and large for gestational age (LGA) are increased in FET cycles when compared with fresh embryo transfer cycles (190) and spontaneous pregnancies (191). The type of FET protocol may be a determining factor for the development of macrosomia/LGA. Thus, in a large retrospective cohort study of 9267 FET cycles, resulting in singleton live birth, the mean birthweight of different FET protocols was compared, including modified-NC $(n=2224)$, mild-OS ( $\mathrm{n}=4299)$ and HRT $(\mathrm{n}=2744)$. A significantly higher mean birthweight was reported in the HRT group when compared with mild-OS. Singleton newborns conceived after FET using HRT were more likely to be LGA than those born after modified-NC or mild-OS (19.92\% vs $16.94 \%$ and $19.29 \%$ vs $16.12 \%$, respectively). The mild-OS group had lower adjusted odds of being macrosomia than the modified-NC group. No significant difference was noted for birthweight, and risk of macrosomia/LGA between modified-NC and mild-OS (192). Furthermore, a significantly higher risk for birth weight $>4,500$ g was observed by other large-scale studies with the HRT protocol than with the modified-NC regimen $(183,185)$. A large retrospective Nordic register-based cohort study reported that, when compared with natural conceptions, the mean birth weight of FET pregnancies become significantly higher starting from gestational week 33 among boys and from gestational week 34 among girls (193).

Regarding obstetric outcomes, the risk of preterm delivery, very preterm delivery and premature rupture of the membrane increase with the HRT protocol as compared to modified-NC (185). In contrast, there appears to be no statistically significant difference in the rate of small for gestational age, placenta previa, or congenital abnormality among modified-NC, mild-OS and HRT protocols (185). Similar neonatal outcome has been reported between HRT and modified-NC cycles (182).

\section{REFERENCES}

1. De Geyter C, Wyns C, Calhaz-Jorge C, de Mouzon J, Ferraretti AP, Kupka M, et al. 20 Years of the European IVF-Monitoring Consortium Registry: What Have We Learned? A Comparison With Registries From Two Other Regions. Hum Reprod (2020) 35(12):2832-49. doi: 10.1093/humrep/deaa250

2. Prevention. CfDCa. 2018, Assisted Reproductive Technology Fertility Clinic Success Rates Report. Atlanta GA: US Dept of Health and Human Services (2020).
With all given increased maternal and obstetric risk factors, some authors suggested a "back to nature" attitude, advocating for more t-NC and modified-NC in future (194).

\section{CONCLUSIONS AND FUTURE PERSPECTIVES}

Despite the worldwide increase in FET for various indications, the search for the best protocol to prepare the endometrium continues. Although HRT and NC (t-NC/modified-NC) are the most commonly used protocols, recent emerging evidence also suggests that mild-OS may be a viable option. Well-designed, powerful RCTs comparing different protocols to prime the endometrium for FET are urgently required; such trials should focus not only on LBR, but also on maternal, obstetrical and neonatal outcomes. Currently, low quality evidence points toward the NC (t-NC/modified-NC) being superior to HRT. Furthermore, in HRT cycles, caution is warranted since the early pregnancy loss rate seems to be alarmingly high in some reports and recent evidence indicates an increased risk of hypertensive disorders in pregnancy in cycles without a corpus luteum. Regarding warmed blastocyst transfer and timing, the evidence suggests $6^{\text {th }}$ day of $\mathrm{P}$ start, LH surge +6 day and hCG +7 day in HRT, t-NC and modified-NC, respectively. Time corrections, due to inter-personal differences in the WOI or day of vitrification (day 5 or 6 ), should be explored further. In the era of personalized medicine, the "one size fits all" strategy does not match the FET cycle. Although not ideal and affected by the route of administration, serum $\mathrm{P}_{4}$ level is a good proxy of endometrial P. A significant inter-personal variation in circulating P in HRT and NC cycles exists and these variations have a major impact on the reproductive outcome. Finally, the place of $\mathrm{P}$ rescue protocols in patients with low serum $\mathrm{P}_{4}$ levels one day prior to warmed blastocyst transfer in HRT and NCFET is likely to be intensively explored in near future.

\section{AUTHOR CONTRIBUTIONS}

SM and HY was involved in the review design, execution, manuscript drafting, and critical discussion of the manuscript. $\mathrm{PH}, \mathrm{SE}$, and EP was involved in the execution, manuscript drafting, and critical discussion of the manuscript. MP, IY, and GB was involved in manuscript drafting, and critical discussion of the manuscript. All authors contributed to the article and approved the submitted version.

3. European IVFMC, European Society of Human R and Embryology, Kupka MS, D'Hooghe T, Ferraretti AP, et al. Assisted Reproductive Technology in Europe, 2011: Results Generated From European Registers by ESHRE. Hum Reprod (2016) 31(2):233-48. doi: 10.1093/ humrep/dev319

4. Kupka MS, Ferraretti AP, de Mouzon J, Erb K, D’Hooghe T, Castilla JA, et al. Assisted Reproductive Technology in Europe, 2010: Results Generated From European Registers by ESHREdagger. Hum Reprod (2014) 29 (10):2099-113. doi: 10.1093/humrep/deu175 
5. Glujovsky D, Pesce R, Sueldo C, Quinteiro Retamar AM, Hart RJ, Ciapponi A. Endometrial Preparation for Women Undergoing Embryo Transfer With Frozen Embryos or Embryos Derived From Donor Oocytes. Cochrane Database Syst Rev (2020) 10:CD006359. doi: 10.1002/ 14651858.CD006359.pub3

6. Weissman A. IVF Worldwide Survey Results: Frozen-Thawed Embryo Transfer. (2017). Available at: https://ivf-worldwide.com/survey/frozenthawed-embryo-transfer/results-frozen-thawed-embryo-transfer.html

7. Lee HJ, Joo JK. When is the Optimal Timing of Frozen Embryo Transfer After Controlled Ovarian Stimulation? Ann Transl Med (2020) 8(7):425. doi: 10.21037/atm.2020.03.41

8. Bosch E, Bulletti C, Copperman AB, Fanchin R, Yarali H, Petta CA, et al. How Time to Healthy Singleton Delivery Could Affect Decision-Making During Infertility Treatment: a Delphi Consensus. Reprod BioMed Online (2019) 38(1):118-30. doi: 10.1016/j.rbmo.2018.09.019

9. Madero S, Rodriguez A, Vassena R, Vernaeve V. Endometrial Preparation: Effect of Estrogen Dose and Administration Route on Reproductive Outcomes in Oocyte Donation Cycles With Fresh Embryo Transfer. Hum Reprod (2016) 31(8):1755-64. doi: 10.1093/humrep/dew099

10. Devroey P, Pados G. Preparation of Endometrium for Egg Donation. Hum Reprod Update (1998) 4(6):856-61. doi: 10.1093/humupd/4.6.856

11. Drakopoulos P, Mat C, Polyzos NP, Santos-Ribeiro S, van de Vijver A, Van Landuyt L, et al. The Impact of Elevated Progesterone on the Initiation of an Artificially Prepared Frozen Embryo Transfer Cycle: a Case Series. Curr Pharm Biotechnol (2017) 18(8):619-21. doi: 10.2174/1389201018666170808125834

12. Navot D, Laufer N, Kopolovic J, Rabinowitz R, Birkenfeld A, Lewin A, et al. Artificially Induced Endometrial Cycles and Establishment of Pregnancies in the Absence of Ovaries. N Engl J Med (1986) 314(13):806-11. doi: 10.1056/ NEJM198603273141302

13. Borini A, Dal Prato L, Bianchi L, Violini F, Cattoli M, Flamigni C. Effect of Duration of Estradiol Replacement on the Outcome of Oocyte Donation. J Assist Reprod Genet (2001) 18(4):185-90. doi: 10.1023/A:1009472416305

14. Bourdon M, Santulli P, Maignien C, Gayet V, Pocate-Cheriet K, Marcellin L, et al. The Deferred Embryo Transfer Strategy Improves Cumulative Pregnancy Rates in Endometriosis-Related Infertility: a Retrospective Matched Cohort Study. PloS One (2018) 13(4):e0194800. doi: 10.1371/ journal.pone. 0194800

15. Sekhon L, Feuerstein J, Pan S, Overbey J, Lee JA, Briton-Jones C, et al. Endometrial Preparation Before the Transfer of Single, Vitrified-Warmed, Euploid Blastocysts: Does the Duration of Estradiol Treatment Influence Clinical Outcome? Fertil Steril (2019) 111(6):1177-85 e3. doi: 10.1016/ j.fertnstert.2019.02.024

16. Vidal C, Giles J, Garrido N, Remohi J, Simon C, Bellver J, et al. GnRH Antagonist for Endometrial Priming in an Oocyte Donation Programme: a Prospective, Randomized Controlled Trial. Reprod BioMed Online (2018) 37 (4):415-24. doi: 10.1016/j.rbmo.2018.06.026

17. Dal Prato L, Borini A, Cattoli M, Bonu MA, Sciajno R, Flamigni C. Endometrial Preparation for Frozen-Thawed Embryo Transfer With or Without Pretreatment With Gonadotropin-Releasing Hormone Agonist. Fertil Steril (2002) 77(5):956-60. doi: 10.1016/S0015-0282(02)02960-6

18. van de Vijver A, Polyzos NP, Van Landuyt L, De Vos M, Camus M, Stoop D, et al. Cryopreserved Embryo Transfer in an Artificial Cycle: is GnRH Agonist Down-Regulation Necessary? Reprod BioMed Online (2014) 29 (5):588-94. doi: 10.1016/j.rbmo.2014.08.005

19. El-Toukhy T, Taylor A, Khalaf Y, Al-Darazi K, Rowell P, Seed P, et al. Pituitary Suppression in Ultrasound-Monitored Frozen Embryo Replacement Cycles. A randomised study. Hum Reprod (2004) 19(4):8749. doi: 10.1093/humrep/deh183

20. Miles RA, Paulson RJ, Lobo RA, Press MF, Dahmoush L, Sauer MV. Pharmacokinetics and Endometrial Tissue Levels of Progesterone After Administration by Intramuscular and Vaginal Routes: a Comparative Study. Fertil Steril (1994) 62(3):485-90. doi: 10.1016/S0015-0282(16)56935-0

21. Bulletti C, De Ziegler D, Giacomucci E, Polli V, Rossi S, Alfieri S, et al. Vaginal Drug Delivery: the First Uterine Pass Effect. Ann N Y Acad Sci (1997) 828:285-90. doi: 10.1111/j.1749-6632.1997.tb48549.x

22. Cicinelli E, de Ziegler D, Bulletti C, Matteo MG, Schonauer LM, Galantino P. Direct Transport of Progesterone From Vagina to Uterus. Obstet Gynecol (2000) 95(3):403-6. doi: 10.1097/00006250-200003000-00017
23. Zarei A, Sohail P, Parsanezhad ME, Alborzi S, Samsami A, Azizi M. Comparison of Four Protocols for Luteal Phase Support in FrozenThawed Embryo Transfer Cycles: a Randomized Clinical Trial. Arch Gynecol Obstet (2017) 295(1):239-46. doi: 10.1007/s00404-016-4217-4

24. Turkgeldi E, Hanege BY, Yildiz S, Keles I, Ata B. Subcutaneous Versus Vaginal Progesterone for Vitrified-Warmed Blastocyst Transfer in Artificial Cycles. Reprod BioMed Online (2020) 41(2):248-53. doi: 10.1016/ j.rbmo.2020.04.007

25. Alsbjerg B, Thomsen L, Elbaek HO, Laursen R, Povlsen BB, Haahr T, et al. Can Combining Vaginal and Rectal Progesterone Achieve the Optimum Progesterone Range Required for Implantation in the HRT-FET Model? Reprod BioMed Online (2020) 40(6):805-11. doi: 10.1016/ j.rbmo.2020.02.007

26. Alsbjerg B, Polyzos NP, Elbaek HO, Povlsen BB, Andersen CY, Humaidan P. Increasing Vaginal Progesterone Gel Supplementation After Frozen-Thawed Embryo Transfer Significantly Increases the Delivery Rate. Reprod BioMed Online (2013) 26(2):133-7. doi: 10.1016/j.rbmo.2012.10.012

27. Enatsu Y, Enatsu N, Kishi K, Iwasaki T, Matsumoto Y, Kokeguchi S, et al. Effectiveness of High-Dose Transvaginal Progesterone Supplementation for Women Who are Undergoing a Frozen-Thawed Embryo Transfer. Reprod Med Biol (2018) 17(3):242-8. doi: 10.1002/rmb2.12096

28. Haddad G, Saguan DA, Maxwell R, Thomas MA. Intramuscular Route of Progesterone Administration Increases Pregnancy Rates During nonDownregulated Frozen Embryo Transfer Cycles. J Assist Reprod Genet (2007) 24(10):467-70. doi: 10.1007/s10815-007-9168-z

29. Kaser DJ, Ginsburg ES, Missmer SA, Correia KF, Racowsky C. Intramuscular Progesterone Versus 8\% Crinone Vaginal Gel for Luteal Phase Support for Day 3 Cryopreserved Embryo Transfer. Fertil Steril (2012) 98(6):1464-9. doi: 10.1016/j.fertnstert.2012.08.007

30. Shapiro DB, Pappadakis JA, Ellsworth NM, Hait HI, Nagy ZP. Progesterone Replacement With Vaginal Gel Versus I.M. Injection: Cycle and Pregnancy Outcomes in IVF Patients Receiving Vitrified Blastocysts. Hum Reprod (2014) 29(8):1706-11. doi: 10.1093/humrep/deu121

31. Leonard PH, Hokenstad AN, Khan Z, Jensen JR, Stewart EA, Coddington CC. Progesterone Support for Frozen Embryo Transfer: Intramuscular Versus Vaginal Suppository Demonstrates No Difference in a Cohort. J Reprod Med (2015) 60(3-4):103-8.

32. Wang $\mathrm{Y}, \mathrm{He} \mathrm{Y}$, Zhao X, Ji X, Hong $\mathrm{Y}$, Wang $\mathrm{Y}$, et al. Crinone Gel for Luteal Phase Support in Frozen-Thawed Embryo Transfer Cycles: a Prospective Randomized Clinical Trial in the Chinese Population. PloS One (2015) 10(7): e0133027. doi: 10.1371/journal.pone.0133027

33. Lightman A, Kol S, Itskovitz-Eldor J. A Prospective Randomized Study Comparing Intramuscular With Intravaginal Natural Progesterone in Programmed Thaw Cycles. Hum Reprod (1999) 14(10):2596-9. doi: 10.1093/humrep/14.10.2596

34. Devine K, Richter KS, Widra EA, McKeeby JL. Vitrified Blastocyst Transfer Cycles With the Use of Only Vaginal Progesterone Replacement With Endometrin Have Inferior Ongoing Pregnancy Rates: Results From the Planned Interim Analysis of a Three-Arm Randomized Controlled Noninferiority Trial. Fertil Steril (2018) 109(2):266-75. doi: 10.1016/ j.fertnstert.2017.11.004

35. Devine K, Richter KS, Jahandideh S, Widra EA, McKeeby JL. Intramuscular Progesterone Optimizes Live Birth From Programmed Frozen Embryo Transfer: a Randomized Clinical Trial. Fertil Steril (2021). doi: 10.1016/ j.fertnstert.2021.04.013

36. Polat M, Mumusoglu S, Bozdag G, Ozbek IY, Humaidan P, Yarali H. Addition of Intramuscular Progesterone to Vaginal Progesterone in Hormone Replacement Therapy in Vitrified-Warmed Blastocyst Transfer Cycles. Reprod BioMed Online (2020) 40(6):812-8. doi: 10.1016/ j.rbmo.2020.01.031

37. Vuong LN, Pham TD, Le KTQ, Ly TT, Le HL, Nguyen DTN, et al. Micronized Progesterone Plus Dydrogesterone Versus Micronized Progesterone Alone for Luteal Phase Support in Frozen-Thawed Cycles (MIDRONE): a Prospective Cohort Study. Hum Reprod (2021) 36(7):182131. doi: 10.1093/humrep/deab093

38. Scott R, Navot D, Liu HC, Rosenwaks Z. A Human In Vivo Model for the Luteoplacental Shift. Fertil Steril (1991) 56(3):481-4. doi: 10.1016/S00150282(16)54544-0 
39. Csapo AI, Pulkkinen MO, Ruttner B, Sauvage JP, Wiest WG. The Significance of the Human Corpus Luteum in Pregnancy Maintenance. I. Preliminary Studies. Am J Obstet Gynecol (1972) 112(8):1061-7. doi: 10.1016/0002-9378(72)90181-0

40. Neumann K, Depenbusch M, Schultze-Mosgau A, Griesinger G. Characterization of Early Pregnancy Placental Progesterone Production by Use of Dydrogesterone in Programmed Frozen-Thawed Embryo Transfer Cycles. Reprod BioMed Online (2020) 40(5):743-51. doi: 10.1016/j.rbmo.2020.01.019

41. Tabibzadeh S. Molecular Control of the Implantation Window. Hum Reprod Update (1998) 4(5):465-71. doi: 10.1093/humupd/4.5.465

42. Franasiak JM, Ruiz-Alonso M, Scott RT, Simon C. Both Slowly Developing Embryos and a Variable Pace of Luteal Endometrial Progression may Conspire to Prevent Normal Birth in Spite of a Capable Embryo. Fertil Steril (2016) 105(4):861-6. doi: 10.1016/j.fertnstert.2016.02.030

43. Escriba MJ, Bellver J, Bosch E, Sanchez M, Pellicer A, Remohi J. Delaying the Initiation of Progesterone Supplementation Until the Day of Fertilization Does not Compromise Cycle Outcome in Patients Receiving Donated Oocytes: a Randomized Study. Fertil Steril (2006) 86(1):92-7. doi: 10.1016/j.fertnstert.2005.12.048

44. van de Vijver A, Polyzos NP, Van Landuyt L, Mackens S, Stoop D, Camus M, et al. What is the Optimal Duration of Progesterone Administration Before Transferring a Vitrified-Warmed Cleavage Stage Embryo? A Randomized Controlled Trial Hum Reprod (2016) 31(5):1097-104. doi: 10.1093/humrep/ dew045

45. van de Vijver A, Drakopoulos P, Polyzos NP, Van Landuyt L, Mackens S, Santos-Ribeiro S, et al. Vitrified-Warmed Blastocyst Transfer on the 5th or 7th Day of Progesterone Supplementation in an Artificial Cycle: a Randomised Controlled Trial. Gynecol Endocrinol (2017) 33(10):783-6. doi: 10.1080/09513590.2017.1318376

46. Ding J, Rana N, Dmowski W. Length of Progesterone Treatment Before Transfer and Implantation Rates of Frozen-Thawed Blastocysts. In: Fertility and Sterility. 2007. ASRM annual meeting (2007) 88(supp 1):S330-S331.

47. Roelens C, Santos-Ribeiro S, Becu L, Mackens S, Van Landuyt L, Racca A, et al. Frozen-Warmed Blastocyst Transfer After 6 or 7 Days of Progesterone Administration: Impact on Live Birth Rate in Hormone Replacement Therapy Cycles. Fertil Steril (2020) 114(1):125-32. doi: 10.1016/ j.fertnstert.2020.03.017

48. Kolibianakis EM, Zikopoulos K, Smitz J, Camus M, Tournaye H, Van Steirteghem AC, et al. Elevated Progesterone at Initiation of Stimulation is Associated With a Lower Ongoing Pregnancy Rate After IVF Using GnRH Antagonists. Hum Reprod (2004) 19(7):1525-9. doi: 10.1093/humrep/ $\operatorname{deh} 272$

49. Panaino TR, Silva JB, Lima MA, Lira P, Areas PC, Mancebo AC, et al. High Progesterone Levels in the Beginning of ICSI Antagonist Cycles and Clinical Pregnancy: Still a Concern? JBRA Assist Reprod (2017) 21(1):11-4. doi: 10.5935/1518-0557.20170004

50. Lee VC, Li RH, Chai J, Yeung TW, Yeung WS, Ho PC, et al. Effect of Preovulatory Progesterone Elevation and Duration of Progesterone Elevation on the Pregnancy Rate of Frozen-Thawed Embryo Transfer in Natural Cycles. Fertil Steril (2014) 101(5):1288-93. doi: 10.1016/ j.fertnstert.2014.01.040

51. Groenewoud ER, Macklon NS, Cohlen BJGroup AS. The Effect of Elevated Progesterone Levels Before HCG Triggering in Modified Natural Cycle Frozen-Thawed Embryo Transfer Cycles. Reprod BioMed Online (2017) 34 (5):546-54. doi: 10.26226/morressier.573c1513d462b80296c98a4d

52. Kahraman S, Sahin Y. Is There a Critical LH Level for hCG Trigger After the Detection of LH Surge in Modified Natural Frozen-Thawed Single Blastocyst Transfer Cycles? J Assist Reprod Genet (2020) 37(12):3025-31. doi: 10.1007/ s10815-020-01974-5

53. Miller PB, Soules MR. The Usefulness of a Urinary LH Kit for Ovulation Prediction During Menstrual Cycles of Normal Women. Obstet Gynecol (1996) 87(1):13-7. doi: 10.1016/0029-7844(95)00352-5

54. Testart J, Frydman R, Feinstein MC, Thebault A, Roger M, Scholler R. Interpretation of Plasma Luteinizing Hormone Assay for the Collection of Mature Oocytes From Women: Definition of a Luteinizing Hormone SurgeInitiating Rise. Fertil Steril (1981) 36(1):50-4. doi: 10.1016/S0015-0282(16) 45617-7
55. Frydman R, Testart J, Feinstein MC, Roger M. Interrelationship of Plasma and Urinary Luteinizing Hormone Preovulatory Surge. J Steroid Biochem (1984) 20(2):617-9. doi: 10.1016/0022-4731(84)90132-8

56. Cekan SZ, Beksac MS, Wang E, Shi S, Masironi B, Landgren BM, et al. The Prediction and/or Detection of Ovulation by Means of Urinary Steroid Assays. Contraception (1986) 33(4):327-45. doi: 10.1016/0010-7824(86) 90095-8

57. Dozortsev DI, Diamond MP. Luteinizing Hormone-Independent Rise of Progesterone as the Physiological Trigger of the Ovulatory Gonadotropins Surge in the Human. Fertil Steril (2020) 114(2):191-9. doi: 10.1016/ j.fertnstert.2020.06.016

58. Irani M, Robles A, Gunnala V, Reichman D, Rosenwaks Z. Optimal Parameters for Determining the LH Surge in Natural Cycle FrozenThawed Embryo Transfers. J Ovarian Res (2017) 10(1):70. doi: 10.1186/ s13048-017-0367-7

59. Frydman R, Testart J, Fernandez H, Arvis P, Belaisch JC. [Prediction of Ovulation]. J Gynecol Obstet Biol Reprod (Paris) (1982) 11(7):793-9.

60. Kosmas IP, Tatsioni A, Fatemi HM, Kolibianakis EM, Tournaye H, Devroey P. Human Chorionic Gonadotropin Administration vs. Luteinizing Monitoring for Intrauterine Insemination Timing, After Administration of Clomiphene Citrate: a Meta-Analysis. Fertil Steril (2007) 87(3):607-12. doi: 10.1016/j.fertnstert.2006.10.003

61. Guida M, Tommaselli GA, Palomba S, Pellicano M, Moccia G, Di Carlo C, et al. Efficacy of Methods for Determining Ovulation in a Natural Family Planning Program. Fertil Steril (1999) 72(5):900-4. doi: 10.1016/S0015-0282 (99)00365-9

62. Hamilton CJ, Wetzels LC, Evers JL, Hoogland HJ, Muijtjens A, de Haan J. Follicle Growth Curves and Hormonal Patterns in Patients With the Luteinized Unruptured Follicle Syndrome. Fertil Steril (1985) 43(4):541-8. doi: 10.1016/S0015-0282(16)48494-3

63. Evers JL. The Luteinized Unruptured Follicle Syndrome. Baillieres Clin Obstet Gynaecol (1993) 7(2):363-87. doi: 10.1016/S0950-3552(05)80136-1

64. Weissman A, Horowitz E, Ravhon A, Steinfeld Z, Mutzafi R, Golan A, et al. Spontaneous Ovulation Versus HCG Triggering for Timing Natural-Cycle Frozen-Thawed Embryo Transfer: a Randomized Study. Reprod BioMed Online (2011) 23(4):484-9. doi: 10.1016/j.rbmo.2011.06.004

65. Fatemi HM, Kyrou D, Bourgain C, Van den Abbeel E, Griesinger G, Devroey P. Cryopreserved-Thawed Human Embryo Transfer: Spontaneous Natural Cycle is Superior to Human Chorionic Gonadotropin-Induced Natural Cycle. Fertil Steril (2010) 94(6):2054-8. doi: 10.1016/j.fertnstert.2009.11.036

66. Litwicka K, Mencacci C, Arrivi C, Varricchio MT, Caragia A, Minasi MG, et al. HCG Administration After Endogenous LH Rise Negatively Influences Pregnancy Rate in Modified Natural Cycle for Frozen-Thawed Euploid Blastocyst Transfer: a Pilot Study. J Assist Reprod Genet (2018) 35(3):449-55. doi: 10.1007/s10815-017-1089-x

67. Montagut M, Santos-Ribeiro S, De Vos M, Polyzos NP, Drakopoulos P, Mackens S, et al. Frozen-Thawed Embryo Transfers in Natural Cycles With Spontaneous or Induced Ovulation: the Search for the Best Protocol Continues. Hum Reprod (2016) 31(12):2803-10. doi: 10.1093/humrep/ dew263

68. Fuh KW, Wang X, Tai A, Wong I, Norman RJ. Intrauterine Insemination: Effect of the Temporal Relationship Between the Luteinizing Hormone Surge, Human Chorionic Gonadotrophin Administration and Insemination on Pregnancy Rates. Hum Reprod (1997) 12(10):2162-6. doi: 10.1093/humrep/12.10.2162

69. Mackens S, Stubbe A, Santos-Ribeiro S, Van Landuyt L, Racca A, Roelens C, et al. To Trigger or Not to Trigger Ovulation in a Natural Cycle for Frozen Embryo Transfer: a Randomized Controlled Trial. Hum Reprod (2020) 35 (5):1073-81. doi: 10.1093/humrep/deaa026

70. Weissman A, Levin D, Ravhon A, Eran H, Golan A, Levran D. What is the Preferred Method for Timing Natural Cycle Frozen-Thawed Embryo Transfer? Reprod BioMed Online (2009) 19(1):66-71. doi: 10.1016/S14726483(10)60048-X

71. Chang EM, Han JE, Kim YS, Lyu SW, Lee WS, Yoon TK. Use of the Natural Cycle and Vitrification Thawed Blastocyst Transfer Results in Better inVitro Fertilization Outcomes: Cycle Regimens of Vitrification Thawed Blastocyst Transfer. J Assist Reprod Genet (2011) 28(4):369-74. doi: 10.1007/s10815-010-9530-4 
72. Fauser BC, Tarlatzis BC, Rebar RW, Legro RS, Balen AH, Lobo R, et al. Consensus on Women's Health Aspects of Polycystic Ovary Syndrome (PCOS): the Amsterdam ESHRE/ASRM-Sponsored 3rd PCOS Consensus Workshop Group. Fertil Steril (2012) 97(1):28-38.e25. doi: 10.1016/ j.fertnstert.2011.09.024

73. Tomas C, Alsbjerg B, Martikainen H, Humaidan P. Pregnancy Loss After Frozen-Embryo Transfer-a Comparison of Three Protocols. Fertil Steril (2012) 98(5):1165-9. doi: 10.1016/j.fertnstert.2012.07.1058

74. Zaat TR, de Bruin JP, Goddijn M, Visser J, Kaaijk EM, Lambalk CB, et al. Home- or Hospital-Based Monitoring to Time Frozen Embryo Transfer in the Natural Cycle? Patient-Reported Outcomes and Experiences From the Antarctica-2 Randomised Controlled Trial. Hum Reprod (2020) 35(4):86675. doi: 10.1093/humrep/deaa040

75. Wu H, Zhou P, Lin X, Wang S, Zhang S. Endometrial Preparation for Frozen-Thawed Embryo Transfer Cycles: a Systematic Review and Network Meta-Analysis. J Assist Reprod Genet (2021). doi: 10.1007/s10815-02102125-0

76. Navot D, Scott RT, Droesch K, Veeck LL, Liu HC, Rosenwaks Z. The Window of Embryo Transfer and the Efficiency of Human Conception In Vitro. Fertil Steril (1991) 55(1):114-8. doi: 10.1016/S0015-0282(16)54069-2

77. Johal JK, Bavan B, Zhang W, Gardner RM, Lathi RB, Milki AA. The Impact of Timing Modified Natural Cycle Frozen Embryo Transfer Based on Spontaneous Luteinizing Hormone Surge. J Assist Reprod Genet (2021) 38 (1):219-25. doi: 10.1007/s10815-020-01994-1

78. Saupstad M, Freiesleben NC, Skouby SO, Andersen LF, Knudsen UB, Petersen KB, et al. Preparation of the Endometrium and Timing of Blastocyst Transfer in Modified Natural Cycle Frozen-Thawed Embryo Transfers (mNC-FET): a Study Protocol for a Randomised Controlled Multicentre Trial. BMJ Open (2019) 9(12):e031811. doi: 10.1136/bmjopen2019-031811

79. Hull MG, Savage PE, Bromham DR, Ismail AA, Morris AF. The Value of a Single Serum Progesterone Measurement in the Midluteal Phase as a Criterion of a Potentially Fertile Cycle ("Ovulation”) Derived Form Treated and Untreated Conception Cycles. Fertil Steril (1982) 37(3):35560. doi: 10.1016/S0015-0282(16)46095-4

80. Bjuresten K, Landgren BM, Hovatta O, Stavreus-Evers A. Luteal Phase Progesterone Increases Live Birth Rate After Frozen Embryo Transfer. Fertil Steril (2011) 95(2):534-7. doi: 10.1016/j.fertnstert.2010.05.019

81. Lee VCY, Li RHW, Yeung WSB, Pak Chung HO, Ng EHY. A Randomized Double-Blinded Controlled Trial of hCG as Luteal Phase Support in Natural Cycle Frozen Embryo Transfer. Hum Reprod (2017) 32(5):1130-7. doi: 10.1093/humrep/dex049

82. Veleva Z, Orava M, Nuojua-Huttunen S, Tapanainen JS, Martikainen H. Factors Affecting the Outcome of Frozen-Thawed Embryo Transfer. Hum Reprod (2013) 28(9):2425-31. doi: 10.1093/humrep/det251

83. Lee VC, Li RH, Ng EH, Yeung WS, Ho PC. Luteal Phase Support Does Not Improve the Clinical Pregnancy Rate of Natural Cycle Frozen-Thawed Embryo Transfer: a Retrospective Analysis. Eur J Obstet Gynecol Reprod Biol (2013) 169(1):50-3. doi: 10.1016/j.ejogrb.2013.02.005

84. Waldman IN, Racowsky C, Disler ER, Thomas A, Lanes A, Hornstein MD. The Clinical Relevance of Luteal Phase Progesterone Support in True Natural Cycle Cryopreserved Blastocyst Stage Embryo Transfers: a Retrospective Cohort Study. Fertil Res Pract (2021) 7(1):4. doi: 10.1186/ s40738-021-00096-5

85. Fauser BC, de Jong D, Olivennes F, Wramsby H, Tay C, Itskovitz-Eldor J, et al. Endocrine Profiles After Triggering of Final Oocyte Maturation With GnRH Agonist After Cotreatment With the GnRH Antagonist Ganirelix During Ovarian Hyperstimulation for In Vitro Fertilization. J Clin Endocrinol Metab (2002) 87(2):709-15. doi: 10.1210/jcem.87.2.8197

86. Casper RF, Yanushpolsky EH. Optimal Endometrial Preparation for Frozen Embryo Transfer Cycles: Window of Implantation and Progesterone Support. Fertil Steril (2016) 105(4):867-72. doi: 10.1016/ j.fertnstert.2016.01.006

87. Eftekhar M, Rahsepar M, Rahmani E. Effect of Progesterone Supplementation on Natural Frozen-Thawed Embryo Transfer Cycles: a Randomized Controlled Trial. Int J Fertil Steril (2013) 7(1):13-20.

88. Horowitz E, Mizrachi Y, Finkelstein M, Farhi J, Shalev A, Gold E, et al. A Randomized Controlled Trial of Vaginal Progesterone for Luteal Phase
Support in Modified Natural Cycle - Frozen Embryo Transfer. Gynecol Endocrinol (2020) 37(1):294-299. doi: 10.1080/09513590.2020.1854717

89. Kim CH, Lee YJ, Lee KH, Kwon SK, Kim SH, Chae HD, et al. The Effect of Luteal Phase Progesterone Supplementation on Natural Frozen-Thawed Embryo Transfer Cycles. Obstet Gynecol Sci (2014) 57(4):291-6. doi: 10.5468/ogs.2014.57.4.291

90. Kyrou D, Fatemi HM, Popovic-Todorovic B, Van den Abbeel E, Camus M, Devroey P. Vaginal Progesterone Supplementation has No Effect on Ongoing Pregnancy Rate in hCG-Induced Natural Frozen-Thawed Embryo Transfer Cycles. Eur J Obstet Gynecol Reprod Biol (2010) 150 (2):175-9. doi: 10.1016/j.ejogrb.2010.02.038

91. Van der Auwera I, Meuleman C, Koninckx PR. Human Menopausal Gonadotrophin Increases Pregnancy Rate in Comparison With Clomiphene Citrate During Replacement Cycles of Frozen/Thawed Pronucleate Ova. Hum Reprod (1994) 9(8):1556-60. doi: 10.1093/ oxfordjournals.humrep.a138748

92. Peeraer K, Couck I, Debrock S, De Neubourg D, De Loecker P, Tomassetti C, et al. Frozen-Thawed Embryo Transfer in a Natural or Mildly Hormonally Stimulated Cycle in Women With Regular Ovulatory Cycles: a RCT. Hum Reprod (2015) 30(11):2552-62. doi: 10.1093/humrep/dev224

93. Casper RF. Letrozole Versus Clomiphene Citrate: Which is Better for Ovulation Induction? Fertil Steril (2009) 92(3):858-9. doi: 10.1016/ j.fertnstert.2007.03.094

94. Miller PB, Parnell BA, Bushnell G, Tallman N, Forstein DA, Higdon HL3rd, et al. Endometrial Receptivity Defects During IVF Cycles With and Without Letrozole. Hum Reprod (2012) 27(3):881-8. doi: 10.1093/humrep/der452

95. Green KA, Zolton JR, Schermerhorn SM, Lewis TD, Healy MW, Terry N, et al. Progesterone Luteal Support After Ovulation Induction and Intrauterine Insemination: an Updated Systematic Review and Meta-Analysis. Fertil Steril (2017) 107(4):924-33 e5. doi: 10.1016/j.fertnstert.2017.01.011

96. Groenewoud ER, Cohlen BJ, Al-Oraiby A, Brinkhuis EA, Broekmans FJ, de Bruin JP, et al. A Randomized Controlled, non-Inferiority Trial of Modified Natural Versus Artificial Cycle for Cryo-Thawed Embryo Transfer. Hum Reprod (2016) 31(7):1483-92. doi: 10.1093/humrep/dew120

97. Greco E, Litwicka K, Arrivi C, Varricchio MT, Caragia A, Greco A, et al. The Endometrial Preparation for Frozen-Thawed Euploid Blastocyst Transfer: A Prospective Randomized Trial Comparing Clinical Results From Natural Modified Cycle and Exogenous Hormone Stimulation With GnRH Agonist. J Assist Reprod Genet (2016) 33(7):873-84. doi: 10.1007/s10815-016-0736-y

98. Agha-Hosseini M, Hashemi L, Aleyasin A, Ghasemi M, Sarvi F, Shabani Nashtaei M, et al. Natural Cycle Versus Artificial Cycle in Frozen-Thawed Embryo Transfer: a Randomized Prospective Trial. Turk J Obstet Gynecol (2018) 15(1):12-7. doi: 10.4274/tjod.47855

99. Lee SJ, SJ, Kwon HC, Kim JW, Lee JH, Jung YJ, Jung JY, et al. Comparison of Clinical Outcome of Frozen-Thawed Embryo Transfer Cycles Between Natural and Artificial (Hormone-Treated) Cycles. Hum Reprod (2008) 23 (suppl_1):i1220-7. doi: 10.1093/humrep/den1077

100. Child TM, Turner E, Mounce K. A Randomized Controlled Trial of Natural Versus GnRH-Agonist/HRT Regimes for Frozen Embryo Replacement. Fertil Steril (2013) 100(3):S146. doi: 10.1016/j.fertnstert.2013.07.1546

101. Kawamura T, Motoyama H, Yanaihara A, Yorimitsu T, Arichi A, Karasawa Y, et al. Clinical Outcomes of Two Different Endometrial Preparation Methods for Cryopreserved-Thawed Embryo Transfer in Patients With a Normal Menstrual Cycle. Reprod Med Biol (2007) 6(1):53-7. doi: 10.1111/ j.1447-0578.2007.00165.x

102. Hancke K, More S, Kreienberg R, Weiss JM. Patients Undergoing FrozenThawed Embryo Transfer Have Similar Live Birth Rates in Spontaneous and Artificial Cycles. J Assist Reprod Genet (2012) 29(5):403-7. doi: 10.1007/ s10815-012-9724-Z

103. Lathi RB, Chi YY, Liu J, Saravanabavanandhan B, Hegde A, Baker VL. Frozen Blastocyst Embryo Transfer Using a Supplemented Natural Cycle Protocol has a Similar Live Birth Rate Compared to a Programmed Cycle Protocol. J Assist Reprod Genet (2015) 32(7):1057-62. doi: 10.1007/s10815015-0499-x

104. Alur-Gupta S, Hopeman M, Berger DS, Gracia C, Barnhart KT, Coutifaris C, et al. Impact of Method of Endometrial Preparation for Frozen Blastocyst Transfer on Pregnancy Outcome: a Retrospective Cohort Study. Fertil Steril (2018) 110(4):680-6. doi: 10.1016/j.fertnstert.2018.05.013 
105. Guan Y, Fan H, Styer AK, Xiao Z, Li Z, Zhang J, et al. A Modified Natural Cycle Results in Higher Live Birth Rate in Vitrified-Thawed Embryo Transfer for Women With Regular Menstruation. Syst Biol Reprod Med (2016) 62(5):335-42. doi: 10.1080/19396368.2016.1199064

106. Liu X, Shi W, Shi J. Natural Cycle Frozen-Thawed Embryo Transfer in Young Women With Regular Menstrual Cycles Increases the Live-Birth Rates Compared With Hormone Replacement Treatment: a Retrospective Cohort Study. Fertil Steril (2020) 113(4):811-7. doi: 10.1016/ j.fertnstert.2019.11.023

107. Hill MJ, Miller KA, Frattarelli JL. A GnRH Agonist and Exogenous Hormone Stimulation Protocol has a Higher Live-Birth Rate Than a Natural Endogenous Hormone Protocol for Frozen-Thawed Blastocyst-Stage Embryo Transfer Cycles: an Analysis of 1391 Cycles. Fertil Steril (2010) 93 (2):416-22. doi: 10.1016/j.fertnstert.2008.11.027

108. Givens CR, Markun LC, Ryan IP, Chenette PE, Herbert CM, Schriock ED. Outcomes of Natural Cycles Versus Programmed Cycles for 1677 FrozenThawed Embryo Transfers. Reprod BioMed Online (2009) 19(3):380-4. doi: 10.1016/S1472-6483(10)60172-1

109. Veleva Z, Tiitinen A, Vilska S, Hyden-Granskog C, Tomas C, Martikainen H, et al. High and Low BMI Increase the Risk of Miscarriage After IVF/ICSI and FET. Hum Reprod (2008) 23(4):878-84. doi: 10.1093/humrep/den017

110. Aleyasin A, Aghahosseini M, Safdarian L, Noorzadeh M, Fallahi P, Rezaeian $Z$, et al. Can Letrozole Plus HMG Protocol Improve Pregnancy Outcomes in Frozen-Thawed Embryo Transfer? RCT Int J Reprod BioMed (2017) 15 (2):83-6. doi: 10.29252/ijrm.15.2.83

111. Sheikhi O, Golsorkhtabaramiri M, Esmaeilzadeh S, Mahouti T, Heidari FN. Reproductive Outcomes of Vitrified Blastocyst Transfer in Modified Natural Cycle Versus Mild Hormonally Stimulated and Artificial Protocols: A Randomized Control Trial. JBRA Assist Reprod (2018) 22(3):221-7. doi: 10.5935/1518-0557.20180040

112. Wright KP, Guibert J, Weitzen S, Davy C, Fauque P, Olivennes F. Artificial Versus Stimulated Cycles for Endometrial Preparation Prior to FrozenThawed Embryo Transfer. Reprod BioMed Online (2006) 13(3):321-5. doi: 10.1016/S1472-6483(10)61434-4

113. Zhang J, Liu H, Wang Y, Mao X, Chen Q, Fan Y, et al. Letrozole Use During Frozen Embryo Transfer Cycles in Women With Polycystic Ovary Syndrome. Fertil Steril (2019) 112(2):371-7. doi: 10.1016/j.fertnstert.2019.04.014

114. Peigne M, Devouche E, Ferraretto X, Gricourt S, Luton D, Patrat C, et al. Higher Live Birth Rate With Stimulated Rather Than Artificial Cycle for Frozen-Thawed Embryo Transfer. Eur J Obstet Gynecol Reprod Biol (2019) 243:144-9. doi: 10.1016/j.ejogrb.2019.10.040

115. Young SL, Savaris RF, Lessey BA, Sharkey AM, Balthazar U, Zaino RJ, et al. Effect of Randomized Serum Progesterone Concentration on Secretory Endometrial Histologic Development and Gene Expression. Hum Reprod (2017) 32(9):1903-14. doi: 10.1093/humrep/dex252

116. Alsbjerg B, Thomsen L, Elbaek HO, Laursen R, Povlsen BB, Haahr T, et al. Progesterone Levels on Pregnancy Test Day After Hormone Replacement Therapy-Cryopreserved Embryo Transfer Cycles and Related Reproductive Outcomes. Reprod BioMed Online (2018) 37(5):641-7. doi: 10.1016/ j.rbmo.2018.08.022

117. Basnayake SK, Volovsky M, Rombauts L, Osianlis T, Vollenhoven B, Healey M. Progesterone Concentrations and Dosage With Frozen Embryo Transfers - What's Best? Aust N Z J Obstet Gynaecol (2018) 58(5):533-8. doi: 10.1111/ ajo. 12757

118. Brady PC, Kaser DJ, Ginsburg ES, Ashby RK, Missmer SA, Correia KF, et al. Serum Progesterone Concentration on Day of Embryo Transfer in Donor Oocyte Cycles. J Assist Reprod Genet (2014) 31(5):569-75. doi: 10.1007/ s10815-014-0199-y

119. Cedrin-Durnerin I, Isnard T, Mahdjoub S, Sonigo C, Seroka A, Comtet M, et al. Serum Progesterone Concentration and Live Birth Rate in FrozenThawed Embryo Transfers With Hormonally Prepared Endometrium. Reprod BioMed Online (2019) 38(3):472-80. doi: 10.1016/ j.rbmo.2018.11.026

120. Gaggiotti-Marre S, Martinez F, Coll L, Garcia S, Alvarez M, Parriego M, et al. Low Serum Progesterone the Day Prior to Frozen Embryo Transfer of Euploid Embryos is Associated With Significant Reduction in Live Birth Rates. Gynecol Endocrinol (2019) 35(5):439-42. doi: 10.1080/ 09513590.2018.1534952
121. Kofinas JD, Blakemore J, McCulloh DH, Grifo J. Serum Progesterone Levels Greater Than $20 \mathrm{Ng} / \mathrm{Dl}$ on Day of Embryo Transfer are Associated With Lower Live Birth and Higher Pregnancy Loss Rates. J Assist Reprod Genet (2015) 32(9):1395-9. doi: 10.1007/s10815-015-0546-7

122. Labarta E, Mariani G, Holtmann N, Celada P, Remohi J, Bosch E. Low Serum Progesterone on the Day of Embryo Transfer Is Associated With a Diminished Ongoing Pregnancy Rate in Oocyte Donation Cycles After Artificial Endometrial Preparation: a Prospective Study. Hum Reprod (2017) 32(12):2437-42. doi: 10.1093/humrep/dex316

123. Labarta E, Mariani G, Paolelli S, Rodriguez-Varela C, Vidal C, Giles J, et al. Impact of Low Serum Progesterone Levels on the Day of Embryo Transfer on Pregnancy Outcome: a Prospective Cohort Study in Artificial Cycles With Vaginal Progesterone. Hum Reprod (2020) 36(3):683-92. doi: 10.1093/ humrep/deaa322

124. Yovich JL, Conceicao JL, Stanger JD, Hinchliffe PM, Keane KN. Mid-Luteal Serum Progesterone Concentrations Govern Implantation Rates for Cryopreserved Embryo Transfers Conducted Under Hormone Replacement. Reprod BioMed Online (2015) 31(2):180-91. doi: 10.1016/ j.rbmo.2015.05.005

125. Gonzalez-Foruria I, Gaggiotti-Marre S, Alvarez M, Martinez F, Garcia S, Rodriguez I, et al. Factors Associated With Serum Progesterone Concentrations the Day Before Cryopreserved Embryo Transfer in Artificial Cycles. Reprod BioMed Online (2020) 40(6):797-804. doi: 10.1016/j.rbmo.2020.03.001

126. Alyasin A, Agha-Hosseini M, Kabirinasab M, Saeidi H, Nashtaei MS. Serum Progesterone Levels Greater Than $32.5 \mathrm{Ng} / \mathrm{Ml}$ on the Day of Embryo Transfer are Associated With Lower Live Birth Rate After Artificial Endometrial Preparation: a Prospective Study. Reprod Biol Endocrinol (2021) 19(1):24. doi: 10.1186/s12958-021-00703-6

127. Boynukalin FK, Gultomruk M, Turgut E, Demir B, Findikli N, Serdarogullari $\mathrm{M}$, et al. Measuring the Serum Progesterone Level on the Day of Transfer can be an Additional Tool to Maximize Ongoing Pregnancies in Single Euploid Frozen Blastocyst Transfers. Reprod Biol Endocrinol (2019) 17(1):102. doi: 10.1186/s12958-019-0549-9

128. Alvarez M, Gaggiotti-Marre S, Martinez F, Coll L, Garcia S, GonzalezForuria I, et al. Individualised Luteal Phase Support in Artificially Prepared Frozen Embryo Transfer Cycles Based on Serum Progesterone Levels: a Prospective Cohort Study. Hum Reprod (2021) 36(6):1552-60. doi: 10.1093/ humrep/deab031

129. Edelman AB, Cherala G, Stanczyk FZ. Metabolism and Pharmacokinetics of Contraceptive Steroids in Obese Women: a Review. Contraception (2010) 82 (4):314-23. doi: 10.1016/j.contraception.2010.04.016

130. Levy T, Yairi Y, Bar-Hava I, Shalev J, Orvieto R, Ben-Rafael Z. Pharmacokinetics of the Progesterone-Containing Vaginal Tablet and its Use in Assisted Reproduction. Steroids (2000) 65(10-11):645-9. doi: 10.1016/S0039-128X(00)00121-5

131. Mackens S, Santos-Ribeiro S, Orinx E, De Munck N, Racca A, Roelens C, et al. Impact of Serum Estradiol Levels Prior to Progesterone Administration in Artificially Prepared Frozen Embryo Transfer Cycles. Front Endocrinol (Lausanne) (2020) 11:255. doi: 10.3389/fendo.2020.00255

132. Yarali H, Polat M, Mumusoglu S, Ozbek IY, Erden M, Bozdag G, et al. Subcutaneous Luteal Phase Progesterone Rescue Rectifies Ongoing Pregnancy Rates in Hormone Replacement Therapy Vitrified-Warmed Blastocyst Transfer Cycles. Reprod BioMed Online (2021) S1472-6483(21) 00187-5. doi: 10.1016/j.rbmo.2021.04.011

133. Jordan J, Craig K, Clifton DK, Soules MR. Luteal Phase Defect: The Sensitivity and Specificity of Diagnostic Methods in Common Clinical Use. Fertil Steril (1994) 62(1):54-62. doi: 10.1016/S0015-0282(16)56815-0

134. Rosenberg SM, Luciano AA, Riddick DH. The Luteal Phase Defect: The Relative Frequency of, and Encouraging Response to, Treatment With Vaginal Progesterone. Fertil Steril (1980) 34(1):17-20. doi: 10.1016/S00150282(16)44831-4

135. Gaggiotti-Marre S, Alvarez M, Gonzalez-Foruria I, Parriego M, Garcia S, Martinez F, et al. Low Progesterone Levels on the Day Before Natural Cycle Frozen Embryo Transfer are Negatively Associated With Live Birth Rates. Hum Reprod (2020) 35(7):1623-9. doi: 10.1093/humrep/deaa092

136. Cha J, Sun X, Dey SK. Mechanisms of Implantation: Strategies for Successful Pregnancy. Nat Med (2012) 18(12):1754-67. doi: 10.1038/nm.3012 
137. Wilcox AJ, Baird DD, Weinberg CR. Time of Implantation of the Conceptus and Loss of Pregnancy. N Engl J Med (1999) 340(23):1796-9. doi: 10.1056/ NEJM199906103402304

138. Craciunas L, Gallos I, Chu J, Bourne T, Quenby S, Brosens JJ, et al. Conventional and Modern Markers of Endometrial Receptivity: a Systematic Review and Meta-Analysis. Hum Reprod Update (2019) 25 (2):202-23. doi: 10.1093/humupd/dmy044

139. Ruiz-Alonso M, Blesa D, Diaz-Gimeno P, Gomez E, Fernandez-Sanchez M, Carranza F, et al. The Endometrial Receptivity Array for Diagnosis and Personalized Embryo Transfer as a Treatment for Patients With Repeated Implantation Failure. Fertil Steril (2013) 100(3):818-24. doi: 10.1016/ j.fertnstert.2013.05.004

140. Diaz-Gimeno P, Ruiz-Alonso M, Blesa D, Bosch N, Martinez-Conejero JA, Alama P, et al. The Accuracy and Reproducibility of the Endometrial Receptivity Array is Superior to Histology as a Diagnostic Method for Endometrial Receptivity. Fertil Steril (2013) 99(2):508-17. doi: 10.1016/ j.fertnstert.2012.09.046

141. Simon C, Gomez C, Cabanillas S, Vladimirov I, Castillon G, Giles J, et al. A 5Year Multicentre Randomized Controlled Trial Comparing Personalized, Frozen and Fresh Blastocyst Transfer in IVF. Reprod BioMed Online (2020) 41(3):402-15. doi: 10.1016/j.rbmo.2020.06.002

142. Bassil R, Casper R, Samara N, Hsieh TB, Barzilay E, Orvieto R, et al. Does the Endometrial Receptivity Array Really Provide Personalized Embryo Transfer? J Assist Reprod Genet (2018) 35(7):1301-5. doi: 10.1007/s10815018-1190-9

143. Neves AR, Devesa M, Martinez F, Garcia-Martinez S, Rodriguez I, Polyzos NP, et al. What is the Clinical Impact of the Endometrial Receptivity Array in PGT-A and Oocyte Donation Cycles? J Assist Reprod Genet (2019) 36 (9):1901-8. doi: 10.1007/s10815-019-01535-5

144. Riestenberg C, Kroener L, Quinn M, Ching K, Ambartsumyan G. Routine Endometrial Receptivity Array in First Embryo Transfer Cycles Does Not Improve Live Birth Rate. Fertil Steril (2021) 114(4):1001-6. doi: 10.1016/ j.fertnstert.2020.09.140

145. Tan J, Kan A, Hitkari J, Taylor B, Tallon N, Warraich G, et al. The Role of the Endometrial Receptivity Array (ERA) in Patients Who Have Failed Euploid Embryo Transfers. J Assist Reprod Genet (2018) 35(4):683-92. doi: 10.1007/ s10815-017-1112-2

146. Kasius A, Smit JG, Torrance HL, Eijkemans MJ, Mol BW, Opmeer BC, et al. Endometrial Thickness and Pregnancy Rates After IVF: a Systematic Review and Meta-Analysis. Hum Reprod Update (2014) 20(4):530-41. doi: 10.1093/ humupd/dmu011

147. Liu KE, Hartman M, Hartman A, Luo ZC, Mahutte N. The Impact of a Thin Endometrial Lining on Fresh and Frozen-Thaw IVF Outcomes: an Analysis of Over 40000 Embryo Transfers. Hum Reprod (2018) 33(10):1883-8. doi: 10.1093/humrep/dey281

148. Shakerian B, Turkgeldi E, Yildiz S, Keles I, Ata B. Endometrial Thickness is Not Predictive for Live Birth After Embryo Transfer, Even Without a Cutoff. Fertil Steril (2021) 116(1):130-7. doi: 10.1016/j.fertnstert.2021.02.041

149. Chen MJ, Yang JH, Peng FH, Chen SU, Ho HN, Yang YS. Extended Estrogen Administration for Women With Thin Endometrium in Frozen-Thawed inVitro Fertilization Programs. J Assist Reprod Genet (2006) 23(7-8):337-42. doi: 10.1007/s10815-006-9053-1

150. Liao X, Li Z, Dong X, Zhang H. Comparison Between Oral and Vaginal Estrogen Usage in Inadequate Endometrial Patients for Frozen-Thawed Blastocysts Transfer. Int J Clin Exp Pathol (2014) 7(10):6992-7.

151. Zolghadri J, Haghbin H, Dadras N, Behdin S. Vagifem is Superior to Vaginal Premarin in Induction of Endometrial Thickness in the Frozen-Thawed Cycle Patients With Refractory Endometria: a Randomized Clinical Trial. Iran J Reprod Med (2014) 12(6):415-20.

152. Xu B, Zhang Q, Hao J, Xu D, Li Y. Two Protocols to Treat Thin Endometrium With Granulocyte Colony-Stimulating Factor During Frozen Embryo Transfer Cycles. Reprod BioMed Online (2015) 30(4):34958. doi: 10.1016/j.rbmo.2014.12.006

153. Chang Y, Li J, Chen Y, Wei L, Yang X, Shi Y, et al. Autologous Platelet-Rich Plasma Promotes Endometrial Growth and Improves Pregnancy Outcome During In Vitro Fertilization. Int J Clin Exp Med (2015) 8(1):1286-90.

154. Sher G, Fisch JD. Vaginal Sildenafil (Viagra): a Preliminary Report of a Novel Method to Improve Uterine Artery Blood Flow and Endometrial
Development in Patients Undergoing IVF. Hum Reprod (2000) 15(4):8069. doi: 10.1093/humrep/15.4.806

155. Ledee-Bataille N, Olivennes F, Lefaix JL, Chaouat G, Frydman R, Delanian S. Combined Treatment by Pentoxifylline and Tocopherol for Recipient Women With a Thin Endometrium Enrolled in an Oocyte Donation Programme. Hum Reprod (2002) 17(5):1249-53. doi: 10.1093/humrep/17.5.1249

156. Weckstein LN, Jacobson A, Galen D, Hampton K, Hammel J. Low-Dose Aspirin for Oocyte Donation Recipients With a Thin Endometrium: Prospective, Randomized Study. Fertil Steril (1997) 68(5):927-30. doi: 10.1016/S0015-0282(97)00330-0

157. Bodombossou-Djobo MM, Zheng C, Chen S, Yang D. Neuromuscular Electrical Stimulation and Biofeedback Therapy may Improve Endometrial Growth for Patients With Thin Endometrium During Frozen-Thawed Embryo Transfer: a Preliminary Report. Reprod Biol Endocrinol (2011) 9:122. doi: 10.1186/1477-7827-9-122

158. Ranisavljevic N, Raad J, Anahory T, Grynberg M, Sonigo C. Embryo Transfer Strategy and Therapeutic Options in Infertile Patients With Thin Endometrium: a Systematic Review. J Assist Reprod Genet (2019) 36 (11):2217-31. doi: 10.1007/s10815-019-01576-w

159. Paulson RJ. Hormonal Induction of Endometrial Receptivity. Fertil Steril (2011) 96(3):530-5. doi: 10.1016/j.fertnstert.2011.07.1097

160. Cicinelli E, De Ziegler D, Morgese S, Bulletti C, Luisi D, Schonauer LM. "First Uterine Pass Effect" is Observed When Estradiol is Placed in the Upper But Not Lower Third of the Vagina. Fertil Steril (2004) 81(5):1414-6. doi: 10.1016/j.fertnstert.2003.12.016

161. Check JH, Graziano V, Lee G, Nazari A, Choe JK, Dietterich C. Neither Sildenafil Nor Vaginal Estradiol Improves Endometrial Thickness in Women With Thin Endometria After Taking Oral Estradiol in Graduating Dosages. Clin Exp Obstet Gynecol (2004) 31(2):99-102. doi: 10.1016/S0015-0282(02) 03043-1

162. Dmowski WP, Michalowska J, Rana N, Friberg J, McGill-Johnson E, DeOrio L. Subcutaneous Estradiol Pellets for Endometrial Preparation in Donor Oocyte Recipients With a Poor Endometrial Response. J Assist Reprod Genet (1997) 14(3):139-44. doi: 10.1007/BF02766129

163. He L, Zhang Z, Li H, Li Y, Long L, He W. Correlation Between Endometrial Thickness and Perinatal Outcome for Pregnancies Achieved Through Assisted Reproduction Technology. J Perinat Med (2019) 48(1):16-20. doi: 10.1515/jpm-2019-0159

164. Kai-Lun Hu AK, Sarah H, Wentao L, Xiaohong L, Runjv Z, Yanjun H, et al. Endometrial Thickness (EMT) in the Prediction of Neonatal Adverse Outcomes in Frozen Cycles for Singleton Pregnancies. Reprod BioMed Online (2021). doi: 10.1016/j.rbmo.2021.04.014

165. Haas J, Smith R, Zilberberg E, Nayot D, Meriano J, Barzilay E, et al. Endometrial Compaction (Decreased Thickness) in Response to Progesterone Results in Optimal Pregnancy Outcome in Frozen-Thawed Embryo Transfers. Fertil Steril (2019) 112(3):503-9.e1. doi: 10.1016/ j.fertnstert.2019.05.001

166. Zilberberg E, Smith R, Nayot D, Haas J, Meriano J, Barzilay E, et al. Endometrial Compaction Before Frozen Euploid Embryo Transfer Improves Ongoing Pregnancy Rates. Fertil Steril (2020) 113(5):990-5. doi: 10.1016/j.fertnstert.2019.12.030

167. Lessey BA, Killam AP, Metzger DA, Haney AF, Greene GL, McCarty KSJr. Immunohistochemical Analysis of Human Uterine Estrogen and Progesterone Receptors Throughout the Menstrual Cycle. J Clin Endocrinol Metab (1988) 67(2):334-40. doi: 10.1210/jcem-67-2-334

168. Bu Z, Yang X, Song L, Kang B, Sun Y. The Impact of Endometrial Thickness Change After Progesterone Administration on Pregnancy Outcome in Patients Transferred With Single Frozen-Thawed Blastocyst. Reprod Biol Endocrinol (2019) 17(1):99. doi: 10.1186/s12958-019-0545-0

169. Ye J, Zhang J, Gao H, Zhu Y, Wang Y, Cai R, et al. Effect of Endometrial Thickness Change in Response to Progesterone Administration on Pregnancy Outcomes in Frozen-Thawed Embryo Transfer: Analysis of 4465 Cycles. Front Endocrinol (Lausanne) (2020) 11:546232. doi: 10.3389/ fendo.2020.546232

170. Riestenberg C, Quinn M, Akopians A, Danzer H, Surrey M, Ghadir S, et al Endometrial Compaction Does Not Predict Live Birth Rate in Single Euploid Frozen Embryo Transfer Cycles. J Assist Reprod Genet (2021) 38(2):407-12. doi: 10.1007/s10815-020-02043-7 
171. Huang J, Lin J, Cai R, Lu X, Song N, Gao H, et al. Significance of Endometrial Thickness Change After Human Chorionic Gonadotrophin Triggering in Modified Natural Cycles for Frozen-Thawed Embryo Transfer. Ann Transl Med (2020) 8(23):1590. doi: 10.21037/atm-20-1459

172. Huang J, Lin J, Gao H, Zhu J, Lu X, Song N, et al. Value of Endometrial Thickness Change After Human Chorionic Gonadotrophin Administration in Predicting Pregnancy Outcome Following Fresh Transfer In Vitro Fertilization Cycles. Arch Gynecol Obstet (2021) 303(2):565-72. doi: 10.1007/s00404-020-05763-4

173. Velarde MC, Aghajanova L, Nezhat CR, Giudice LC. Increased MitogenActivated Protein Kinase Kinase/Extracellularly Regulated Kinase Activity in Human Endometrial Stromal Fibroblasts of Women With Endometriosis Reduces 3',5'-Cyclic Adenosine 5'-Monophosphate Inhibition of Cyclin D1. Endocrinology (2009) 150(10):4701-12. doi: 10.1210/en.2009-0389

174. Houshdaran S, Nezhat CR, Vo KC, Zelenko Z, Irwin JC, Giudice LC. Aberrant Endometrial DNA Methylome and Associated Gene Expression in Women With Endometriosis. Biol Reprod (2016) 95(5):93. doi: 10.1095/ biolreprod.116.140434

175. Santulli P, Borghese B, Noel JC, Fayt I, Anaf V, de Ziegler D, et al. Hormonal Therapy Deregulates Prostaglandin-Endoperoxidase Synthase 2 (PTGS2) Expression in Endometriotic Tissues. J Clin Endocrinol Metab (2014) 99 (3):881-90. doi: 10.1210/jc.2013-2950

176. Kao LC, Germeyer A, Tulac S, Lobo S, Yang JP, Taylor RN, et al. Expression Profiling of Endometrium From Women With Endometriosis Reveals Candidate Genes for Disease-Based Implantation Failure and Infertility. Endocrinology (2003) 144(7):2870-81. doi: 10.1210/en.2003-0043

177. Ahn SH, Khalaj K, Young SL, Lessey BA, Koti M, Tayade C. ImmuneInflammation Gene Signatures in Endometriosis Patients. Fertil Steril (2016) 106(6):1420-31 e7. doi: 10.1016/j.fertnstert.2016.07.005

178. Bourdon M, Santulli P, Kefelian F, Vienet-Legue L, Maignien C, PocateCheriet K, et al. Prolonged Estrogen (E2) Treatment Prior to FrozenBlastocyst Transfer Decreases the Live Birth Rate. Hum Reprod (2018) 33 (5):905-13. doi: 10.1093/humrep/dey041

179. Bourdon M, Maignien C, Pocate-Cheriet K, Plu Bureau G, Marcellin L, Patrat C, et al. The Freeze-All Strategy After IVF: Which Indications? Reprod BioMed Online (2021) 42(3):529-45. doi: 10.1016/j.rbmo.2020.11.013

180. Surrey ES, Katz-Jaffe M, Kondapalli LV, Gustofson RL, Schoolcraft WB. GnRH Agonist Administration Prior to Embryo Transfer in Freeze-All Cycles of Patients With Endometriosis or Aberrant Endometrial Integrin Expression. Reprod BioMed Online (2017) 35(2):145-51. doi: 10.1016/ j.rbmo.2017.05.004

181. Zeng MF, Zhou X, Duan JL. Stimulated Cycle Versus Artificial Cycle for Frozen Embryo Transfer in Patients With Polycystic Ovary Syndrome: a Meta-Analysis. Gynecol Endocrinol (2021) 37(4):294-9. doi: 10.1080/ 09513590.2020 .1867976

182. Ginstrom Ernstad E, Wennerholm UB, Khatibi A, Petzold M, Bergh C. Neonatal and Maternal Outcome After Frozen Embryo Transfer: Increased Risks in Programmed Cycles. Am J Obstetrics Gynecol (2019) 221(2):126 e1e18. doi: 10.1016/j.ajog.2019.03.010

183. Asserhoj LL, Spangmose AL, Aaris Henningsen AK, Clausen TD, Ziebe S, Jensen RB, et al. Adverse Obstetric and Perinatal Outcomes in 1,136 Singleton Pregnancies Conceived After Programmed Frozen Embryo Transfer (FET) Compared With Natural Cycle FET. Fertil Steril (2021) 115(4):947-56. doi: 10.1016/j.fertnstert.2020.10.039

184. Makhijani R, Bartels C, Godiwala P, Bartolucci A, Nulsen J, Grow D, et al. Maternal and Perinatal Outcomes in Programmed Versus Natural VitrifiedWarmed Blastocyst Transfer Cycles. Reprod Biomed Online (2020) 41 (2):300-8. doi: 10.1016/j.rbmo.2020.03.009
185. Hu KL, Zhang D, Li R. Endometrium Preparation and Perinatal Outcomes in Women Undergoing Single-Blastocyst Transfer in Frozen Cycles. Fertil Steril (2021) 115(6):1487-94. doi: 10.1016/j.fertnstert.2020.12.016

186. Conrad KP. Emerging Role of Relaxin in the Maternal Adaptations to Normal Pregnancy: Implications for Preeclampsia. Semin Nephrol (2011) 31(1):15-32. doi: 10.1016/j.semnephrol.2010.10.003

187. Conrad KP, Baker VL. Corpus Luteal Contribution to Maternal Pregnancy Physiology and Outcomes in Assisted Reproductive Technologies. Am J Physiol Regul Integr Comp Physiol (2013) 304(2):R69-72. doi: 10.1152/ ajpregu.00239.2012

188. von Versen-Hoynck F, Narasimhan P, Selamet Tierney ES, Martinez N, Conrad KP, Baker VL, et al. Absent or Excessive Corpus Luteum Number Is Associated With Altered Maternal Vascular Health in Early Pregnancy. Hypertension (2019) 73(3):680-90. doi: 10.1161/HYPERTENSIONAHA. 118.12046

189. von Versen-Hoynck F, Schaub AM, Chi YY, Chiu KH, Liu J, Lingis M, et al. Increased Preeclampsia Risk and Reduced Aortic Compliance With In Vitro Fertilization Cycles in the Absence of a Corpus Luteum. Hypertension (2019) 73(3):640-9. doi: 10.1161/HYPERTENSIONAHA.118.12043

190. Litzky JF, Boulet SL, Esfandiari N, Zhang Y, Kissin DM, Theiler RN, et al. Effect of Frozen/Thawed Embryo Transfer on Birthweight, Macrosomia, and Low Birthweight Rates in US Singleton Infants. Am J Obstetrics Gynecol (2018) 218(4):433 e1- e10. doi: 10.1016/j.ajog.2017.12.223

191. Elias FTS, Weber-Adrian D, Pudwell J, Carter J, Walker M, Gaudet L, et al. Neonatal Outcomes in Singleton Pregnancies Conceived by Fresh or Frozen Embryo Transfer Compared to Spontaneous Conceptions: a Systematic Review and Meta-Analysis. Arch Gynecol Obstetrics (2020) 302(1):31-45. doi: 10.1007/s00404-020-05593-4

192. Wang B, Zhang J, Zhu Q, Yang X, Wang Y. Effects of Different Cycle Regimens for Frozen Embryo Transfer on Perinatal Outcomes of Singletons. Hum Reprod (2020) 35(7):1612-22. doi: 10.1093/humrep/deaa093

193. Terho AM, Pelkonen S, Opdahl S, Romundstad LB, Bergh C, Wennerholm UB, et al. High Birth Weight and Large-for-Gestational-Age in Singletons Born After Frozen Compared to Fresh Embryo Transfer, by Gestational Week: a Nordic Register Study From the CoNARTaS Group. Hum Reprod (2021) 36(4):1083-92. doi: 10.1093/humrep/deaa304

194. Lawrenz B, Coughlan C, Melado L, Fatemi HM. The ART of Frozen Embryo Transfer: Back to Nature! Gynecol Endocrinol (2020) 36(6):479-83. doi: $10.1080 / 09513590.2020 .1740918$

Conflict of Interest: HY, EP, and GB declare receipt of honorarium for lectures from Merck and research grants from Merck and Ferring. SE declares receipt of unrestricted research grants from Merck and lecture fees from Merck and Med.E.A. PH has received unrestricted research grants from MSD and Merck, as well as honoraria for lectures from MSD, Merck, Gedeon-Richter, Theramex, and IBSA.

The remaining authors declare that the research was conducted in the absence of any commercial or financial relationships that could be construed as a potential conflict of interest.

Copyright (c) 2021 Mumusoglu, Polat, Ozbek, Bozdag, Papanikolaou, Esteves, Humaidan and Yarali. This is an open-access article distributed under the terms of the Creative Commons Attribution License (CC BY). The use, distribution or reproduction in other forums is permitted, provided the original author(s) and the copyright owner(s) are credited and that the original publication in this journal is cited, in accordance with accepted academic practice. No use, distribution or reproduction is permitted which does not comply with these terms. 